
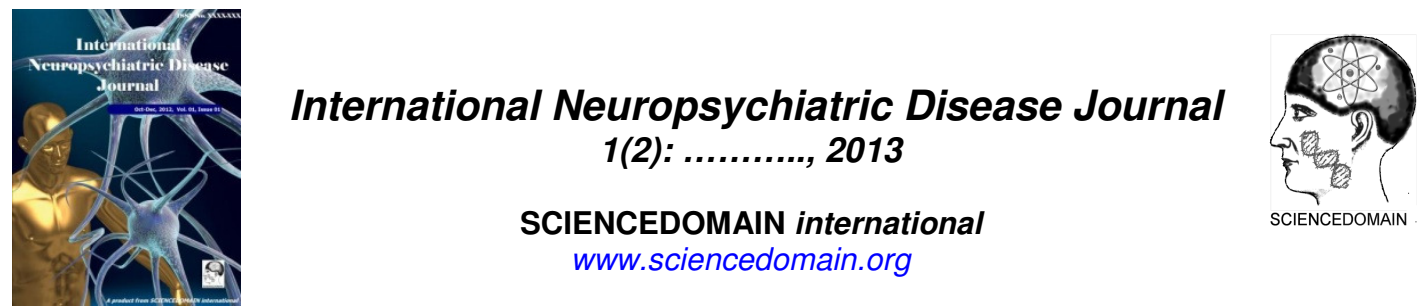

\title{
The Development of Cannabidiol as a Psychiatric Therapeutic: a Review of Its Antipsychotic Efficacy and Possible Underlying Pharmacodynamic Mechanisms
}

\author{
Shahin AM Jalali ${ }^{1 \star}$ and William E. Johnson ${ }^{1}$ \\ ${ }^{1}$ Life and Health Sciences, Aston University, Birmingham, UK.
}

Authors' contributions

Author SAMJ conceived of the review, analysed the original papers, and composed the first draft. Both authors collaborated to design, and manage, the review. Both authors read and approved of the final manuscript.

Review Article

Received $30^{\text {th }}$ July 2013 Accepted $22^{\text {nd }}$ September 2013 Published $11^{\text {th }}$ October 2013

\section{ABSTRACT}

Cannabidiol (CBD), a once-considered inert cannabis constituent, is one of two primary constituents of cannabis, alongside delta-9-tetrahydrocannabinol ( $\triangle 9-\mathrm{THC} / \mathrm{THC})$. In the last 30 years, CBD has become implicated with a range of pharmaceutical mechanisms of great therapeutic interest and utility. This review details the literature speculating CBD's attenuation of psychotic symptoms, particularly in light of a marked elevation in mean THC concentrations, and a concomitant decline in CBD concentrations in the prevalent U.K street market cannabis derivatives since c. 2000. CBD is purported to exhibit pharmacology akin to established atypical antipsychotics, whilst THC has been implicated with the precipitation of psychosis, and the induction of associated symptoms. The aim of the review was to clarify the conjecture surrounding CBD's antipsychotic efficacy, before going on to detail prominent theories about its associated pharmacodynamics. Were CBD's antipsychotic efficacy established, then there is potential for major latent anthropological repercussions to manifest, such as significant elevations in psychosis manifestations in the U.K. The review found a largely affirmative body of evidence asserting CBD's antipsychotic efficacy. CBD exhibited capacity to attenuate natural and artificially induced psychoses in both animal and human cohorts, 
the latter of which included individuals considered resistant to conventional treatment. CBD also shows promising potential for use as an antipsychotic drug for Parkinson's disease (PD) patients with psychosis, owing to its low rate of extra-pyramidal side-effect induction. A range of potential pharmacological mechanisms behind CBD's neuroleptic pharmacology are outlined, with particular emphasis on its prevention of the hydrolysis and reuptake of the endogenous cannabinoid, anandamide. However, given the nebular aetiological basis for psychoses, explicit conclusions on how CBD attenuates psychotic symptoms remains to be determined.

Keywords: Cannabidiol; CBD; antipsychotic; THC; psychosis; schizophrenia; anandamide; cannabinoid.

\section{INTRODUCTION}

Cannabidiol (CBD) is one the constituents of Cannabis. Although the research looking into the antipsychotic efficacy of CBD has increased in the last decade, there's still a necessity for more to be done. The literature is not overwhelmingly in support of the postulation, and our lack of knowledge about cannabinoids, the endogenous cannabinoid system, and their interaction, renders our knowledge of neurophysiology, psychopharmacology, and psychiatric therapeutics, as severely deficient. As such, this review seeks to not only serve as a tool for demystifying the stigma which surrounds Cannabis amongst laymen and scholars alike, but also as a comprehensive and largely chronological reference text for anyone who's already established, or interested in furthering their erudition, in the field of cannabinoids, the endocannabinoid system, cannabidiol, and the development of psychiatric therapeutics. Although preceding reviews have provided invaluable insight and clarity to the question of CBD's antipsychotic efficacy, this review expounds on salient points which previous papers have failed to be address.

\section{CANNABIS' HISTORICAL CONTEXT}

The antiquity of Hemp utilisation purportedly traces back c. 10,000 B.C. to south-eastern regions of Taiwan, where evidence of its use in rope manufacture has been documented, prior to its significant incorporation as one of the five major "grains" in Neolithic Chinese civilisations, in spite of its technical classification as a nut [1-3].Over the succeeding centuries Cannabis utility permeated westwards, through India into the middle-east, becoming established in Asia as a significant ceremonial and medicinal plant for centuries from c.650 B.C, and acknowledged by the likes of Avicinna (Ibn Sīnā) in his magnum opus, Canon of Medicine (c. 1000 A.D.) [4].

Hemp's introduction to western medicine is largely accredited to W.B. O'Shaughnessy, who published his discoveries of the plant's therapeutic- sedative, appetite stimulant, anxiolytic, antiemetic, analgesic, and anticonvulsive- properties, in 1843 [5]. His publication concluded with the conviction that "we possess no remedy at all equal to this in anti-convulsive and anti-neuralgic power".

By the turn of the $20^{\text {th }}$ century, the production and prescription of hemp extracts and tinctures were common for ailments ranging from pains, whooping cough, and asthma, however this swiftly and almost completely stopped by the middle of the century; primarily 
due to the interdiction of Cannabis in the west, but also owing to variability in effects, extract potency, and introduction of more stable synthetic pharmaceutical substitutes [6].

\section{CANNABIS AS A SOURCE OF EXOGENOUS PHYTOCANNABINOIDS}

Cannabis is a genus of the Cannabaceae family, with the most pertinent species with regard to recreational, medical, and research utility being Cannabis sativa and Cannabis indica, of which the former is capable of growing in both temperate and tropical climates [7-8]. More than 60 of the known 460 chemicals within Cannabis are classified as phytocannabinoids- as light is a requisite for their synthesis- which, following the isolation and identification of naturally occurring endogenous (endo)cannabinoids and their respective receptors in 1999, greatly piqued the research community's interest towards the exogenous light-synthesised (phyto)cannabinoids of Cannabis [9-10]. Glandular trichomesprotruding from the stem and leaves of the Cannabis plant are the primary, if not sole, site of Hemp's cannabinoid biosynthesis; the principle constituents being considered to be $\Delta^{9}$-tetrahydrocannabinol (THC) and cannabidiol (CBD), which are synthesised in accordance to genetically determined ratios [11-12].

\subsection{Delta-9-Tetrahydrocannabinol (THC)}

Since its isolation by Gaoni and Mechoulam in 1964, Delta-9-Tetrahydrocannabinol $(\Delta 9$ $\mathrm{THC} / \mathrm{THC}$ ), a phytocannabinoid which exhibits a mechanism of action, and receptor affinity, ostensibly analogous to that of the endocannabinoid anandamide (albeit with a lesser affinity for CB1 and lower still for CB2 receptors), was long attributed to be the primary compound responsible for the therapeutic and intoxicating psychotomimetic effects of Cannabisprincipally due to its partial agonism (Ki value in the low nanomolar range) of the G-protein coupled cannabinoid receptors (CBR) CB1R and CB2R [8,13-15]. Although under the influence of a multitude of variables- environment, subjective mindset, personality, and tolerance- THC's effects are considered biphasic, in that low doses induces analgesic, euphoric, sedative/hypnotic, antidepressant, anxiolytic, and myorelaxant properties amongst others, while numerous of the effects which are considered unfavourable, such as cognitive impairment, anxiety, depersonalisation, and perceptual distortion, manifest as a result of its high or rapid dosage administration $[8,12,16]$.

\subsection{Cannabidiol (CBD)}

CBD- first isolated in 1940, prior to its subsequent structural elucidation in 1963- is the predominant cannabinoid constituent in Cannabis varieties typically cultivated for fibre and edible oils, resulting in a stockier stem and taller plan; there is generally less psychotropic THC synthesised in these varieties comparative to those grown for recreational use [17-19]. In spite of having been identified more than two centuries prior to THC, CBD has received comparatively limited attention from the scientific research community; the paucity of research interest towards CBD is arguably, in part, the result of early studies, which suggested $\mathrm{CBD}$ had a lack of cannabinoid $(\mathrm{CB})$ receptor affinity, and as such potentially inert or insignificant pharmacology [9,20-21]. Since the turn of the millennium the field of CBD research gained momentum as a plethora therapeutic effects were discovered, including anxiolytic, neuroprotective, sedative/hypnotic, antiemetic, anti-arthritic, anti-inflammatory, and antipsychotic effects [8-9,12,22-30] (for an extensive outline of the ostensible pharmacological effects and underlying pharmacodynamics the reader is referred to the articles of Pertwee [15] and Izzo [27]). This review is principally focused on assessing the 
research literature which has emerged concerning CBD's ostensible antipsychotic pharmacology and its potential development as a psychiatric therapeutic, in addition to the postulated underlying pharmacokinetic mechanisms behind it.

\section{CANNABIS \& PSYCHOSIS}

The interest in cannabidiol's antipsychotic efficacy lies partly in Cannabis' early association with psychosis. Kurt Beringer- accredited to the conception of the term 'model psychosis'proposed, in the first systematic study to utilise defined dosages, that the effects of Cannabis induced psychopathological alterations analogous to psychoses such as schizophrenia [31]. Subsequently, studies into the psychotomimetic properties of Cannabis and its professed causal link with the manifestation of psychoses- largely attributed to the action of THC following its isolation, owing to its explicit CB receptor agonism- lead to apprehension of its utility; this is still a disputed field of research however. Some studies have asserted a link between Cannabis use and induction of psychoses; one study has asserted a two-fold increase in the risk of schizophrenia manifestation as a result of frequent use [32]. On the other hand Frisher's [33] study into schizophrenia manifestations in the U.K between the years 1996 and 2005 found no evidence of elevated schizophrenia and psychosis rates. The study investigated the years 1996 to 2005, giving 3 reasons for this: (1) frequent Cannabis use increases relative risk of schizophrenia manifestation by $1.8-3.1$; (2) considerable increase in U.K. Cannabis use from the mid-1970s; and (3) elevated risk of schizophrenia manifestation for 20 years from first use.

If CBD's antipsychotic efficacy was to be affirmed, then it would lead to justifiable scrutiny of Frisher's [33] chosen years of analysis, for studies have asserted that the U.K street market was predominantly saturated with Cannabis containing on average substantially higher concentration of CBD prior to 2000 , before being principally replaced by high THC, low CBD, Cannabis of the sinsemilla variety (Table 1) [11,34]. This may not only explain the largely torpid, and at times declining, incidences of schizophrenia and psychosis in the scrutinised years, but it may also allow us to anticipate marked elevation in incidences of psychosis between the years 2020-2030, if Frisher's [33] third assertion is proved to be correct.

\section{THE ENDOGENOUS (ENDO)-CANNABINOID SYSTEM}

The retrograde Cannabinoid signalling system is considered to comprise of the cannabinoid CB1 and CB2 receptors, the endogenously synthesised (endo)-cannabinoid ligands, and endocannabinoid biosynthesis/inactivation mechanisms [27]. The Cannabinoid CB1 and CB2 receptors- which fall under the super-family of G-protein-coupled receptors- were identified and cloned in the early 1990s, and comprises a large portion of human neurological pathways, being expressed in the brain at a higher prevalence than all the dopamine, noradrenaline and serotonin receptors combined, while being up to ten times more prevalent than opioid receptors [16,35-36]. The distribution of the cannabinoid receptor sub-types were subsequently elucidated, with CB1 receptors having been identified as located primarily in central and peripheral neurones while being expressed, though to a lesser degree, in non-neuronal cells like immune cells; CB2 receptors were found to be prevalent in immune cells, though they're also present and expressed in neuronal cells of the central nervous system [15,37-40]. 
Table 1. The mean THC:CBD concentrations (\%) of the U.K street market Cannabis derivatives in 2004/5, their historic prevalence, method of production and cultivation. Information has been taken and adapted from $[11,34]$

\begin{tabular}{|c|c|c|c|}
\hline $\begin{array}{l}\text { Cannabis } \\
\text { Variety }\end{array}$ & $\begin{array}{l}\text { Method of Production } \\
\text { and Cultivation }\end{array}$ & $\begin{array}{l}\text { Mean } \\
\text { THC:CBD } \\
\text { content in the } \\
\text { U.K street } \\
\text { market as of } \\
2004 / 5(\%)\end{array}$ & $\begin{array}{l}\text { Prevalence and } \\
\text { Availability in the U.K }\end{array}$ \\
\hline Hashish & $\begin{array}{l}\text { Comprised entirely by the } \\
\text { compression of the } \\
\text { Cannabis' trichomes, } \\
\text { which forms a malleable, } \\
\text { often black, solid } \\
\text { derivative. }\end{array}$ & $3.54: 4.17$ & $\begin{array}{l}\text { Comprised approximately } \\
70 \% \text { of the 'street market' } \\
\text { up until c. } 2000 \text {, hashish } \\
\text { has subsequently become } \\
\text { the least readily available } \\
\text { Cannabis derivative. This } \\
\text { reduction in CBD rich } \\
\text { Cannabis availability has } \\
\text { potential implications to } \\
\text { the welfare of smokers, if } \\
\text { its antipsychotic effect is } \\
\text { acknowledged }\end{array}$ \\
\hline $\begin{array}{l}\text { Herbal } \\
\text { Marijuana }\end{array}$ & $\begin{array}{l}\text { Often grown and imported } \\
\text { from tropical or sub- } \\
\text { tropical countries. The } \\
\text { outdoor grown, pollinated } \\
\text { female plants are } \\
\text { compressed and contain } \\
\text { the foliar and floral } \\
\text { material. }\end{array}$ & $2.14:<0.10$ & $\begin{array}{l}\text { Prevalence has increased } \\
\text { since c. } 2000 \text { s, though at a } \\
\text { much lower rate than } \\
\text { sinsemilla }\end{array}$ \\
\hline $\begin{array}{l}\text { Herbal } \\
\text { Sinsemilla } \\
\text { (Spanish } \\
\text { derivation } \\
\text { meaning } \\
\text { seedless)- } \\
\text { commonly } \\
\text { termed } \\
\text { 'skunk' }\end{array}$ & $\begin{array}{l}\text { Predominantly grown } \\
\text { indoors in countries where } \\
\text { it is illegality and } \\
\text { unsuitable weather } \\
\text { prevents out-door } \\
\text { production, as is the case } \\
\text { for the U.K. The crop is } \\
\text { all-female so as to inhibit } \\
\text { seed production and to } \\
\text { maximise cannabinoid } \\
\text { production and yield. } \\
\text { Specialised technical } \\
\text { equipment is used to } \\
\text { maximise growth- these } \\
\text { selectively bred varieties } \\
\text { are harvested for their } \\
\text { glowering buds and their } \\
\text { disproportionately high } \\
\text { THC content. }\end{array}$ & $13.98:<0.10$ & $\begin{array}{l}\text { As of c. } 2000 \text { sinsemilla } \\
\text { has become the most } \\
\text { available Cannabis } \\
\text { variety, potentially } \\
\text { comprising of more than } \\
70 \% \text { of the U.K street } \\
\text { market, whereas it was } \\
\text { the least predominant } \\
\text { prior to c.2000. Given } \\
\text { THC's implication with } \\
\text { precipitated psychosis, } \\
\text { juxtaposed with CBD's } \\
\text { ostensible antipsychotic } \\
\text { efficacy, then the drastic } \\
\text { increase in sinsemilla } \\
\text { prevalence has the } \\
\text { potential to result in } \\
\text { serious implications to the } \\
\text { psychological welfare of } \\
\text { U.K Cannabis smokers }\end{array}$ \\
\hline
\end{tabular}


$\mathrm{N}$-arachidonoylethanolamine (anandamide- from the Sanskirt word ananda, or 'bliss') and 2arachidonoylglycerol (2AG), were the first two endogenously synthesised (endo)cannabinoids to be discovered; they were revealed to be capable of agonising both the identified cannabinoid CB1 and CB2 receptor sub-groups, while their synthesis was found to take place in response to elevations in intracellular calcium concentrations [15,4145].It is generally accepted that CB1 is responsible for retrograde regulatory inhibition of neurotransmitters such as glutamate and GABA, following endocannabinoid (namely anandamide and 2AG) biosynthesis, release, and agonism, subsequent to postsynaptic intracellular calcium increases induced by certain neurotransmitter stimulation- this presynaptic neuron activation by ligands released from the postsynaptic cleft is termed retrograde signalling (Reader is advised to refer to the figure within Ashton's paper [16]). CB2 is considered responsible for the mediation of messenger release, such as cytokines in immune cells, as well as potential modulation of immune cell migration within and outside the central nervous system $[15-16,46]$.

As such, the endocannabinoid system seemingly acts as a form of modulatory system, functioning to attenuate the potential to be overwhelmed by excitatory or inhibitory neuronal activity. Because of its regulatory action to the activity of other neurotransmitter systemsparticularly glutamate and GABA, but also serotonin- postulations as to its dysfunctions inducing states of neuropsychological extremes typical in psychosis have been conceivedmania and hyperarousal at one end, juxtaposed with anhedonia and depression at the other [47-51].

This is supported by research implicating the glutamatergic and GABAergic neurotransmitter systems with states of psychoses; given the dopamine antagonism exhibited by conventional antipsychotics, current literature has greatly appealed to the notion of a dysfunctioning dopaminergic signalling pathway, and as such the thesis of cannabinoid-dopaminergic signal pathway interaction is of particular significance [47,52-54]. A lack of a direct cannabinoid system interaction with dopaminergic signalling pathways is plausible, due to little evidence for CB1 receptor presence on dopaminergic neurones in the basal ganglia and limbic system, though studies have revealed increased meso-prefrontal dopaminergic activity in conjunction with dopamine neurone excitation in the ventral tegmentum and substantia nigra consequent to cannabinoid administration- perhaps this is the result of GABAergic and glutamatergic activation and interaction with the dopaminergic signalling pathway, the latter of which is considered in a recent analysis of cannabinoid-dopaminergic pathway interaction [47,55-59]. Thus, seeing as the aforementioned neurological pathways have been implicated with the manifestation of artificial and naturally occurring states of psychosis (in both human and animal subjects) a necessity for the elucidation of the elaborate conjecture surrounding the constituents of the endocannabinoid system is warranted- particularly in light of its role in neuronal signal modulation $[9,49,52,60-61]$.

\section{ENDOCANNABINOID SYSTEM INTERRACTION WITH EXOGENOUS CANNABINOIDS}

It has been posited that the presence of CBD, and the other trace cannabinoids(in conjunction with the primary psychotropic substance, THC), produces somewhat of a refined 'entourage effect', making for synergistic activity in Cannabis extracts that is absent in isolated CBD or THC administration- a thesis which is supported by studies suggesting that the effects of Cannabis extracts are up to four times greater intensity in one study on 
animals \& humans, and $330 \%$ greater in another done on mice alone, than that expected of their known THC content [12,62-64].

Anandamide, the endogenous cannabinoid which exhibits a mode of action analogous to that of THC, has of late been identified as a potential indicator for psychosis manifestation following its eight-fold elevation in the cerebrospinal fluids of subjects who were treated with atypical antipsychotics or were antipsychotic-naive; this elevation was absent in healthy volunteers and those treated with typical antipsychotics [13,24]. This gives rise to conjecture as to the potential role of anandamide as an innate biological response to psychosis manifestation, perhaps as a form of natural antipsychotic, working to attenuate its manifestation. This research has further implications to the scrutiny of CBD's antipsychotic efficacy, in light of studies reporting its role in preventing anandamide hydrolysis (by fatty acid amide hydrolase (FAAH)), and reuptake [22,65-66]. Furthermore, CBD has been found to elevate blood and brain THC levels, whilst exhibiting an inhibitory effect on THC metabolism, reducing the presence of its metabolite (THC-COOH and $11-\mathrm{OH}-\mathrm{THC}$ ) subsequent to CBD pretreatment [65-66]. Thus, in light of research having established antagonistic properties of CBD to CB receptor agonists, in conjunction with its aforementioned modulations of anandamide, THC, glutamatergic, and GABAergic signalling pathways, one can appreciate that the effect of the cannabinoid system on states of psychosis is very much convoluted, interrelated and in need of elucidation- apt given the abundance of aetiological postulations for psychoses [22,29,47,65-66]. Consequently, our knowledge of pharmacology, neurophysiology, and psychiatric disorders, are severely impeded and in need of explication, considering the wide spread influence (and our severely deficient understanding of the role and impact) of the endocannabinoid system.

\section{PARADIGMS CONCERNING THE STUDIES LOOKING INTO CANNABIDIOL'S ANTIPSYCHOTIC EFFICACY}

\subsection{Neurochemical Hypotheses and Induction of Psychosis in Test Subjects}

Tests exploring the antipsychotic efficacy of Cannabidiol utilise either human models hitherto afflicted with psychoses or humans/animals artificially with artificially induced psychosis following exposure to psychotomimetic substances, which are believed to emulate a certain component of the hypothesised aetiological, and pathophysiological, dysfunction of psychiatric disorders, in accordance with relevant neurochemical hypotheses [49,52,60-61].

\subsection{Dopaminergic Induction of Psychosis}

Schizophrenia has been strongly implicated with a dysfunctioning (overactive) dopaminergic signalling pathway, the notion of which is supported by the fact that modern (typical) antipsychotics- which attenuate symptomatic behaviours such as attention \& cognitive deficits, social withdrawal, and hyperlocomotion subsequent to administration- are predominantly dopamine D2 receptor antagonists [58,60,67].Thus dopamine D2 agonists like apomorphine and amphetamines are used as psychotomimetics to artificially induce dopaminergic psychosis- resulting in the manifestation of stereotyped behaviours indicative of a state of psychosis- by stimulating dopamine release, whilst inhibiting the dopamine transporters' capacity for reuptake [6].Accordingly, the dopaminergic theory of schizophrenia is considered one of two principle models employed studies which seek to induce artificial states of psychosis in healthy human and murine models. 


\subsection{Glutamatergicmodels of Psychosis}

Dysfunctional glutamatergic neurotransmission is the second significant postulated neurochemical hypothesis for psychosis. This is supported by studies showing that schizophrenic patient sexhibit deficits in glutamatergic neurotransmission, which is further validated by the attenuative efficacy of atypical antipsychotic like clozapine, which primarily exhibit glutamate $\mathrm{N}$-methyl-D-aspartate (NMDA) receptor agonism, but also loose, transient interaction with acetylcholine, histamine, serotonin, and dopamine pathways [6,60-61,67-68]. This explains the use of NMDA receptor antagonists- such as, MK-801, and ketamine (or its related compound, phencyclidine) - as psychotomimetics for the induction and study of artificially induced glutamate-associated psychosis $[6,49,68-69]$.

\subsection{Flaws in Contemporary Antipsychotics}

The antipsychotic efficacy of a neuroleptic/antipsychotic drug is largely gauged by the degree to which it is capable of attenuating the stereotyped, psychosis-associated, behavioural symptoms in either natural or artificially induced states of psychosis.

The use of typical antipsychotics are particularly effective in the attenuation of 'positive' psychotic symptoms, such as agitation, delusions, and hallucinations; they are however generally ineffective- and at times augmentative- to 'negative' symptoms of chronic psychosis, which include impaired cognition manifested as alogia, deficient working memory, social withdrawal, and apathy [67].

Furthermore, owing to the dopaminergic antagonism of typical antipsychotics, patients are often at risk of hyperprolactinaemia; the disruption to prolactin's secretory regulation is due to a resulting lack of dopamine release from the hypothalamic arcuate nucleus, which prevents its usual tonic inhibition of the anterior-pituitary mammotrophic cells $[6,67]$.

Moreover, Typical antipsychotics are associated with a high risk, even at low concentrations, of extrapyramidal side-effects, ranging from (tardive) dyskinesia, to dystonia and akathisia; the severity of these side-effects are dose-dependent, and as such the use of neuroleptic on Parkinson's patients are problematic [70-71].

Atypical antipsychotics on the other hand have shown a capacity to attenuate the psychotic behaviours and hyperlocomotion induced by artificial psychosis models, not only at lower doses than typical antipsychotics, but also with lower incidences of both extrapyramidal and prolactin side-effects; speculatively this is the result of their comparatively lower dopamine D2 affinity, juxtaposed with serotonin $5-\mathrm{HT}_{2 \mathrm{~A}}$ receptors affinity $[6,67]$.

Having said this, one can understand why research suggesting that CBD possesses a pharmacological profile akin to modern atypical antipsychotics galvanised the literature assessing the legitimacy of the assertions, and the underlying mechanisms of action underpinning its pharmacology. Prominent pre-clinical and clinical studies regarding CBD's antipsychotic pharmacology, their study designs, and significant assertions, are consequently detailed, prior to a summation of the prominent pharmacokinetic theories, so as to form a concise, mostly chronological, narrative of the fields' progression. 


\section{PRECLINICAL INVESTIGATIONS INTO THE ANTIPSYCHOTIC EFFICACY OF CBD USING RODENT MODELS OF MANIA}

Speculation into cannabidiol's antipsychotic properties first emerged in 1982, when, in an interactive study involving healthy volunteers, CBD displayed attenuating capacity against THC-induced stereotyped behaviours associated with states of psychosis- namely disturbance of perceptions, disconnection of thought, depersonalisation, and resistance to communication [72]. Support emerged later that year in a study observing Cannabis users admitted into a psychiatric hospital in South Africa, which reported a significantly high frequency of acute psychotic symptoms in patients who had used Cannabis devoid of cannabidiol $[9,73]$.

Research into cannabidiol's neuroleptic potential subsequently underwent a state of torpor for nearly a century, until a study comparing its effects to the established typical antipsychotic Haloperidol, wherein rat models with dopamine-associated psychosis induced by apomorphine administration were utilised [74]. Murine models of psychosis are typically assessed in accordance with stereotypical behaviours considered indicative of a psychotic state, such as vulnerability to stress in the form of stress-induced hyperlocomotion, increased biting and sniffing, attentional and cognitive deficits which impair performance in tests, and social withdrawal $[9,60]$. Both CBD $(60 \mathrm{mg} / \mathrm{kg})$ and haloperidol $(0.5 \mathrm{mg} / \mathrm{kg})$ were shown to dose-dependently reduce the stereotyped behaviours induced by the dopamine agonistic apomorphine [74]. Furthermore, an elevation in the serum prolactin resulted subsequent to both haloperidol $(0.125,0.25,0.5 \mathrm{mg} / \mathrm{kg})$ and CBD $(240 \mathrm{mg} / \mathrm{kg})$ administration. Even at doses as high as $480 \mathrm{mg} / \mathrm{kg}$ CBD did not induce a cataleptic response in the rats; unlike haloperidol, which did so at doses as low as $0.25 \mathrm{mg} / \mathrm{kg}$.

This was further supported by a study by Moreira [75], which utilised both dopamineric and glutamatergic animal (mice) models of psychosis- induced by amphetamine and subanaesthetic doses of ketamine administration, respectively- in a study assessing cannabidiol's $(15,30,60 \mathrm{mg} / \mathrm{kg})$ efficacy in inhibiting the consequently induced hyperlocomotion, compared to haloperidol $(0.15,0.3,0.6 \mathrm{mg} / \mathrm{kg})$ and the atypical antipsychotic clozapine $(1.25,2.5,5.0 \mathrm{mg} / \mathrm{kg})$. The study employed the catalepsy test so as to assess clozapine, haloperidol, and CBD's potency of catalepsy induction. The severity of the induced catalepsy is used as an indicator of the drug's probability of inducing extrapyramidal side-effects in human subjects; the test involves recording the time a mouse remains stagnant with its paw on a horizontal bar after having it placed there [76]. Cannabidiol, unlike clozapine and haloperidol, produced neither detrimental cataleptic or sedative effects. Furthermore, 30 minutes subsequent to an injection of the psychotomimetic amphetamine/ketamine, the distance travelled by the mice was measured for a 10 minute period; it was found that both cannabidiol $(30,50 \mathrm{mg} / \mathrm{kg})$ and clozapine $(5 \mathrm{mg} / \mathrm{kg})$ showed effectiveness at inhibiting stress-related hyperlocomotion in the mice, whereas haloperidol did not [75].

A year later Long [77] conducted a study to test the neuroleptic capacity of both CBD (5 $\mathrm{mg} / \mathrm{kg}$ ) and clozapine $(4 \mathrm{mg} / \mathrm{kg})$ on glutamatergic MK-801-induced psychosis in mice, and found that both substances proved capable of attenuating the models' MK-801-induced prepulse inhibition (PPI) disruption- a functional gauge of sensorimotor gating which has been shown to be impaired in patients with schizophrenia [78-79]. 
Malone [80] sought to evaluate the effects of both THC and CBD administration on the social interaction of Sprague-Dawley rats and found that cannabidiol and THC- when administered in isolation- induced no effect and reduced social interaction, respectively. As such the study looked at the effect of cannabidiol $(20 \mathrm{mg} / \mathrm{kg}$ ) pre-treatment prior to THC $(1 \mathrm{mg} / \mathrm{kg}$ ) administration, and found that the pre-treatment induced an attenuating affect to the social withdrawal induced by the latter, enforcing the postulated antipsychotic effect of CBD.

In a study consisting of two experiments- the first of which comprised of two treatment paradigms- Valvassori [81] looked into the effects of CBD on dexamphetamine-induced oxidative stress in rats. The first experiment's primary paradigm- termed 'reversal treatment'involved the daily intraperitoneal administration of saline or the psychotomimetic dexamphetamine $(2 \mathrm{mg} / \mathrm{kg})$ for 14 days, with twice daily injections of saline or CBD $(15,30$, $60 \mathrm{mg} / \mathrm{kg}$ ) from days 8 to 14 . The secondary 'prevention treatment' paradigm involved twice daily intraperitoneal injections of saline or CBD, with daily injections of saline or dexamphetamine from days 8 to 14. The second experiment scrutinised CBD's (30 \& 60 $\mathrm{mg} / \mathrm{kg}$ ) capacity to thwart dexamphetamine-induced carbonyl group formation in the prefrontal cortex. Despite finding that CBD was successfully able to increase brain-derived neurotrophic factor (BDNF) expression, while lessening the dexamphetamine-induced oxidative protein damage in the striatum and hippocampus, Valvassori [81] reported that CBD had no attenuative effect to the hyperlocomotion induced by dexamphetamine in either of the two experiments. As such this study brings into contention not only CBD's neuroleptic legitimacy, but also the hypothesis that CBD's antioxidant and neuroprotective capacity may possibly be behind its antipsychotic efficacy [82].

Long [83] set out to investigate, amongst others, the effect that acute $(1,5,10,50 \mathrm{mg} / \mathrm{kg})$ and chronic (1, 5, 10, $50 \mathrm{mg} / \mathrm{kg}$; over 8 weeks) CBD exposure would have on the dexamphetamine-induced hyperlocomotion and PPI test paradigms in C57BL/6jArc mice. Positive and significant increases in the PPI of the mice was reported as a result of both acute $(1,5,50 \mathrm{mg} / \mathrm{kg})$ and chronic (1 mg/kg at 18) CBD administration. On the other hand, only chronic administration of CBD $(50 \mathrm{mg} / \mathrm{kg})$ showed a capacity to attenuate dexamphetamine $(5 \mathrm{mg} / \mathrm{kg}$ )-induced hyperlocomotion, suggesting that CBD exhibits antagonism to substances which induced psychotic symptoms subsequent to long term exposure, despite Moreira [75] having reported successful attenuation of amphetamineinduced hyperlocomotion by acute CBD administration. Zuardi [82] explicate that this discrepancy could have arisen from differences in drugs used to induce stereotyped behaviours, rodent strains, and administration regimes.

In a pioneering study Klein [66] looked into cannabidiol's potentiation of THC pharmacodynamics and psychotomimetic properties in adolescent rats, finding evidence conflicting with research suggesting that CBD possesses antipsychotic activity. Cannabidiol was not only found to exacerbated the social withdrawal and anxiogenic effects induced in rats administered with THC, but it also served to augment the blood and brain THC levels, while lowering the concentrations of its metabolites, 11-OH-THC (which exhibits similar pharmacological activity) and the non-psychoactive $\mathrm{THC}-\mathrm{COOH}$. Interestingly a previousstudy had recognised CBD's augmentative effects on THC, so long as CBD administration occurred 15-60 minutes prior [84]. This supports a hypothesis which suggests that CBD metabolites, rather than CBD itself, are responsible for the purported inhibition of THC metabolism and elevation of THC concentration in serum and the brain. Furthermore, Klein [66] looked into the ostensible involvement of the serotonin 5- $\mathrm{HT}_{1 \mathrm{~A}}$ receptor in $\mathrm{CBD}$ pharmacodynamics after studies reported that the receptor undergoes up-regulated following chronic cannabidiol treatment [48]. Despite Zavitsanou's [48] conjecture not being 
concurrent with the study's results, Klein [66] postulates the possibility of the rats having been resistant to chronic cannabinoid effects on the $5-\mathrm{HT}_{1 \mathrm{~A}}$ receptor due to the high basal density of the receptor in the rats utilised, while Zuardi [82] suggests that factors such as rodent strains, CBD administration regime, and variability in psychotomimetic drugs utilised could aid elucidation of the experimental discrepancies.

Klein's (2011) study, which refutes the antipsychotic efficacy of CBD, is somewhat supported by a study which scrutinised cannabidiol's capacity to attenuate behaviours considered indicative to positive and negative schizophrenic symptoms (hyperlocomotion, social withdrawal, and PPI deficits) in rats subsequent to the induction of a glutamatergic, MK-801induced, psychosis [68]. When administered alone CBD was shown to induce detrimental PPI deficits as well as increased hyperactivity, though no effect on social behaviour was observed. When administered subsequent to the psychotomimetic MK-801, CBD $(3,10,30$ $\mathrm{mg} / \mathrm{kg}$ ) showed no capacity to attenuate the disruption of PPI and hyperactivity, though it did partially attenuate the manifested social withdrawal at $3 \& 10 \mathrm{mg} / \mathrm{kg}$. For comparison clozapine was also tested, and found to exhibit a capacity to attenuate both MK-801-induced hyperlocomotion and social withdrawal (at 3 and $1 \mathrm{mg} / \mathrm{kg}$, respectively), but it only partially reduced the PPI disruption of the mice. Based on the results the study concluded with the assertion that cannabidiol exhibited primarily prosychotic, along with partial antipsychotic, activity.

Having said this, Cannabidiol's atypical antipsychotic profile and its ostensibly low risk of extra-pyramidal side-effects received support from Guimarães' [85] study, which investigated mouse brain activation patterns subsequent to administration of CBD (120 mg/kg), clozapine $(20 \mathrm{mg} / \mathrm{kg}$ ), and haloperidol (1 mg/kg) (atypical and typical antipsychotics, respectively). Fos immunoreactive neurones (FIr) were used as an indicator of brain activation- for Fos protein expression is considered indicative of antipsychotic drug activity. It was found that Cannabidiol, haloperidol, and to a lesser extent clozapine, administration resulted in an increase in the presence of FIr neurone in a brain region implicated with the pathophysiology of schizophrenia, namely the limbic-related nucleus accumbens, while only haloperidol induced a significant increase in the motor-related dorsal striatum [85]. Although later studies have criticised this study for not investigating other brain structures associated with the manifesting of negative symptoms (such as the prefrontal cortex) [86], it nonetheless provides a strong biological basis for the hypothesis that CBD possesses an antipsychotic profile akin to atypical antipsychotics.

Gururajan [87] set out to assess CBD's capacity to reverse the MK-801-induced hyperactivity, attention-span and social interaction deficits, in a novel testing paradigm involving physical separation of Sprague-Dawley rats. Having been assured of the paradigm's validity, it was reported that although both CBD $(3 \mathrm{mg} / \mathrm{kg})$ and clozapine $(1,3$, $\mathrm{mg} / \mathrm{kg}$ ) pre-treatment failed to control the induced attention-span impairments, they both successfully mitigated the psychomotor agitation and social investigative behaviour deficits; CBD not only normalised, but improved the latter to beyond control levels. This is most interesting given that study [68] reported only partial attenuation of MK-801-induced social withdrawal in rats following CBD pre-treatment.

Long [88] utilised putative animal models of mania- transmembrane domain neuregulin 1 mutant (Nrg1 TM HET) mice which exhibit stereotyped psychotic behaviours (namely PPI deficits and hyperlocomotion), in addition to diminished 5- $\mathrm{HT}_{2 \mathrm{~A}}$ receptor binding density in the substantial nigra, so as to test the neuroleptic effects of acute and chronic CBD administration. The mice received intraperitoneal vehicle or $\operatorname{CBD}(1,50,100 \mathrm{mg} / \mathrm{kg})$ 
injections for 21 days, while the behaviour, blood CBD concentrations, and receptor binding in specific brain regions relevant to the pathophysiology of schizophrenia were scrutinised. The social interaction of mutant mice was selectively increased- in spite of an unaltered baseline level of interaction- following long term CBD (50 \& $100 \mathrm{mg} / \mathrm{kg}$ ) treatment. Furthermore, an increase in the PPI of mutant mice following acute CBD $(100 \mathrm{mg} / \mathrm{kg}$ ) administration was observed, showing pharmacology indicative of antipsychotic efficacy; though repeat administration lead to a diminishing of this effect, raising questions as to the validity of the mutant models' pharmacodynamics- a doubt the authors dismiss since CBD blood concentrations did not differ between genotypes. Despite not having reduced the hyperlocomotion of the mutant mice, the wild-type mice were affected by CBD's anxiolytic effects upon repeated administration. As such Long [88] reasoned that Nrg1 modulates both the acute and long-term neurobehavioural effects of CBD, for none of the schizophreniarelated phenotypes were reversed as a result of CBD administration to the mutant mice, contradicting ostensible evidence as to CBD's antipsychotic efficacy.

Spontaneously hypertensive rats (SHR) exhibit positive (hyperlocomotion), and negative (deficits in social interaction), stereotyped schizophrenic behaviour- both of which have been shown to be ameliorated by typical \& atypical, and atypical antipsychotics, respectively [89]. As such, Almeida [86] utilised SHRs to scrutinise CBD's atypical antipsychotic \& anxiolytic pharmacological profile, and found that none of the acute doses of CBD used $(1,5,15,30$, and $60 \mathrm{mg} / \mathrm{kg}$ ) had attenuating effects on the SHRs' stereotyped hyperlocomotion and deficits in social interaction- whereas the lowest dose of CBD $(1 \mathrm{mg} / \mathrm{kg})$ successfully lowered the anxiety (and as such increased the social interaction)- of control rats. Almeida [86] crucially postulates that one reason for the lack of observed antipsychotic efficacy from CBD may be due to a need for SHRs to be exposed to chronic doses of CBD prior to the manifestation of antipsychotic effects.

The discrepancy seen within the animal studies has been postulated to arise number of factors, including differences in protocols, rodent strains and species, animal models, CBD administration regimes, and variability in psychotomimetic drugs utilised $[82,86]$.

\section{INVESTIGATIONS ON HEALTHY HUMAN SUBJECTS WITH ARTIFICIALLY INDUCED PSYCHOSIS}

So as to allow CBD to be administered to humans, confirmation of its safety and toxicity profile were first required. A crucial early investigation reported no significant detrimental clinical, neurological, or psychiatric repercussions to a cohort of healthy volunteers following one month of chronic CBD (10-400mg/day dosages) administration [90]. This was subsequently confirmed by a study wherein CBD (700mg/day fixed dosage) was administered chronically to Huntington's disease patients [91]. A later investigation found that high daily doses of CBD $(1,500 \mathrm{mg})$ are well tolerated in humans [92]. Administration of $\mathrm{CBD}$ through differing routes has also been shown to not induce significant toxic side effects in humans [82]. A study engaged in a thorough in vivo and in vitro investigation into the safety of CBD administration across a broad range of concentrations found that no notable side or toxic effects were induced, other than minor side effects such as the inhibition of hepatic drug metabolism [93]. As such these safety studies verified the majority of the preclinical animal research findings, which found CBD to be safe for acute and chronic administration over a large range of dosages, allowing for the safe progression of the research onto human studies. 
Given the reasonably successful testing of cannabidiol's safety profile and antipsychotic efficacy on animal models with artificially induced psychosis in preclinical trials, studies employing human models subsequently gained impetus towards the turn of the millennium.

One method of assessing the efficacy of neuroleptic drugs in human models involves gauging the extent to which they attenuate the subject's impaired perception of the Binocular Depth Inversion (BDI) test illusory image. Psychosis, whether artificially induced or not, impairs the perception of the illusory image, and as such the extent to which antipsychotics mitigate this impairment is used as a gauge of antipsychotic efficacy [94]. One study tested the ability of CBD to attenuate a significant perceptual impairment of the illusory image that was induced in healthy volunteers by administration of the psychotomimetic THC homologue, Nabilone [95]. The team reported that the impairment was mitigated subsequent to cannabidiol (200mg) administration, before going on to propose that CBD may exhibit CB1 receptor antagonism- a postulation which was substantiated in a later study [27].

Zuardi [6] utilised healthy volunteers with ketamine-induce psychosis in a double-blind crossover procedural study which assessed the extent to which CBD $(600 \mathrm{mg})$ attenuated the manifest depersonalisation in the nine volunteers which were compared. Separated by a week, the subjects sat through two sessions wherein either placebo or CBD was administered. After 65 minutes of rest a sub-anaesthetic dose of ketamine was administered during the first minute, followed by a maintenance dose after 30 minutes, so as to ensure desired serum concentrations. CBD administration was shown to markedly attenuate the subsequent ketamine-induced state of depersonalisation in the majority of subjects, as assessed in accordance with the Clinician-Administered Dissociative States Scale (CADSS) (which gauges factors like depersonalisation, derealisation, and amnesia), affirming the hypothesised atypical antipsychotic pharmacological profile of CBD [6].

Morgan [10] conducted a study investigating the CBD and THC content of 140 individuals' hair and found that three distinct groups were present: THC-only, THC+CBD, and no cannabinoid. The study utilised the short form Oxford Liverpool Inventory of Life Experience (OLIFE) questionnaires, together with Peter's Delusion Inventory (PDI), to index the individual's propensity for psychosis manifestation. Morgan [10] discerned that the THC-only group exhibited higher levels of delusional thinking and positive schizophrenia symptoms than those who fell into the $\mathrm{THC}+\mathrm{CBD}$ and no cannabinoid groups. The results are comparatively tenuous however, for there was an inability to directly infer CBD:THC ratios, owing to a lack of comprehension of how cannabinoids are integrated into hair.

Cannabidiol's capacity to attenuate memory loss and psychotic symptoms was assessed in a study which scrutinised the effects of the chosen Cannabis of 134 Cannabis smokers [96]. Contrary to the majority of preceding evidence it was found that the levels of cannabidiol present in the Cannabis smoked by the subjects did not significantly affect the degree of psychotic symptoms exhibited, having observed an elevation in symptoms regardless of which of the two groups (high or low CBD) that they fell into. However, they did conclude that lower levels of $\mathrm{CBD}$ lead to significant hindrance in subject prose recall capability, suggesting a mitigating role against THC-induced memory-impairment; the study postulated that $\mathrm{CB} 1$ receptor antagonism by $\mathrm{CBD}$ was behind the effects, in accordance with the postulations of a couple of preceding studies [29,95].

Morgan's 2011 study [82] set out to assess the effects of acute exposure to smoked Cannabis in a naturalistic setting by looking at the ratios of THC and CBD found in the hair of 120 Cannabis smokers, of which 66 were reported as daily and 54 recreational smokers, classifying them in accordance with both the presence and absence of CBD, and high or low 
concentrations of THC. CBD was found to exhibit protective effects on both positive psychotic symptoms and recognition memory impairments in the daily Cannabis users with high concentrations of THC in their smoked Cannabis, providing promising support of the potential ameliorating effect CBD exhibits to THC's ostensible psychotomimetic effects [82].

Hallack [49] utilised ketamine to induce psychosis on 10 healthy volunteers in a double-blind procedure so as to gauge the efficacy of CBD $(600 \mathrm{mg})$ and placebo in two distinct randomised sessions. The subjects were subsequently assessed in accordance with the aforementioned Clinician Administered Dissociative State Scale (CADSS) and the Brief Psychiatric Rating Scale (BPRS)- which is sub-divided into four factors; positive, negative, anxiety/depression, and psychomotor activation- so as to allow assessment of their behavioural and subjective effects [49,97-98]. The study reported significantly augmented psychomotor activation and a non-significant reduction in the ketamine-induced depersonalisation following $\mathrm{CBD}$ administration, contrary to evidence suggesting its antipsychotic efficacy. Hallack [49] posited that a convoluted mutual interaction of CBD and ketamine, on both the glutamatergic and GABAergic signalling pathways, is behind the complex pattern of interactive behavioural effects reported in the study.

Schubart [99]amassed and utilised information on the Cannabis use of 1877 Dutch individuals who frequently use the same type of Cannabis ( $>60 \%$ of occasions), together with subclinical psychiatric experiences by using the Community Assessment of Psychic Experiences (CAPE), in a voluntary web-based cross-sectional study. This was done so as to allow scrutiny of psychotic experiences in relation to the CBD and THC content of their chosen Cannabis variety. A significant inverse relationship between cannabidiol content and self-reported positive psychotic experiences was found, though it is important to note that the experiences excluded negative symptoms and depression. Despite lacking significant legitimacy owing to its reliance on anecdotal evidence, the study nonetheless provides support for the notion that CBD exhibits a degree of antipsychotic efficacy.

\section{CBD'S ANTIPSYCHOTIC EFFICACY ON PSYCHIATRIC PATIENTS IN A CLINICAL SETTING}

CBD's aforesaid lack of toxicity, combined with the promising results from the aforementioned studies, allowed for investigations into CBD's antipsychotic efficacy to progress onto testing in psychiatric patients, starting in 1995 with a single-case preclinical trial involving a 19 year old woman with schizophrenia who had reported considerable hormonal side effects consequent to treatment with conventional antipsychotics. The administration of up to $1,500 \mathrm{mg} /$ day for 4 weeks resulted in an improvement of her condition analogous to the improvement induced by haloperidol, as shown by her cross-criteria Brief Psychiatric Rating Scale (BPRS) scores- a decline in her condition was observed following treatment cessations (See figure of patient $A$ in article) [92]. This provided a strong initial research foundation from which clinical studies could go on to investigate further, owing to the strong supporting evidence for the hypothesised antipsychotic effects of CBD which it provides.

A later investigation by the same team from the previously mentioned also looked into cannabidiol monotherapy on 3 treatment resistant schizophrenics [100]. The 22-23 year old subjects were exposed to 5 days of placebo administration followed by cannabidiol from days 6-35 (utilising incremental doses from $40 \mathrm{mg} /$ day up to $1280 \mathrm{mg} /$ day), then 5 days of placebo, before being given 15 days of Olanzapine (atypical antipsychotic). One psychiatrist 
administered the doses, while two dose-blind psychiatrists screened for adverse effects whilst assessing the attenuation of psychotic symptoms, in accordance with BPRS (See figures of patients B-D in article) [92]. While only one patient exhibited an improvement to their condition, the other two subjects were considered refractory due to their lack of response to previous antipsychotic treatment, even to clozapine. Interestingly, two of the patients- one who responded to CBD monotherapy and another who didn't- displayed a deterioration of symptoms subsequent to cessation of CBD therapy. Though the study reported a weak antipsychotic efficacy, it provided invaluable clarification as to the tolerability and toxicity of CBD dosages, with no side effects having been exhibited, even at the highest dose administered.

However, a year later a four-week, double-blind, controlled trial comparing the effects of CBD monotherapy with the atypical antipsychotic amisulpride in 42 schizophrenic or schizophreniform subjects (DSM-IV diagnosed) was reported [101] (as cited in [9] and $[76,106]$. Both courses of treatment resulted in a reduction of reported psychotic symptoms after 2-4 weeks, with the only factor having differentiated CBD from amisulpride being lower incidences of detrimental side effects (weight gain, extra-pyramidal side symptoms, and hyperprolactinaemia). As such this study provided a great deal of support for CBD's hypothesised atypical antipsychotic pharmacology, given its low association with detrimental side-effects $[100,106]$.

The treatment of Parkinson's disease (PD) patients (up to 30\% of whom exhibit incidence of psychotic symptoms) poses a great difficulty to psychiatric clinicians for three reasons, (1) decreasing doses of anti-Parkinsonian drugs will typically result in exacerbation of motor symptoms, (2) the use of typical antipsychotics may lead to augmentation of motor symptoms, as previously discussed with regards to extra-pyramidal side effects, and (3) In spite of clozapine's high efficacy in treatment of Parkinson's, it has the capacity to induce detrimental haematological and neurological side effects, amongst others [70,71,76]. As such, the necessity for a safe and well-tolerated treatment for psychosis in PD patients lead to a pioneering open trial looking into the efficacy, tolerability, and safety of CBD treatment in 6 PD patients who'd exhibited at least 3 months of psychotic symptoms [102]. A flexible dose of $C B D$, starting at $150 \mathrm{mg} /$ day and going up to $400 \mathrm{mg} /$ day was used in conjunction with the PD patients' normal treatment. Cannabidiol did not deteriorate motor function, and in fact led to a reduction in their symptoms- though this did not achieve statistical significance. Furthermore, cannabidiol induced a significant attenuation of psychotic experiences, in accordance with the BPRS and Parkinson Psychosis Questionnaire evaluation criteria, with no adverse effects reported as a result of treatment. This study not only supports the theory that CBD possesses an atypical antipsychotic profile, but it also extends its potential utility to the treatment of psychosis in PD patients; though it was acknowledge that further studies utilising controlled randomised double-blind assays would be necessary to conclusively affirm this.

An investigation [103] asserted, after a 4 week double-blind trial, that CBD was not only comparable to amisulpride in its neuroleptic capacity, but also exhibited a markedly superior side-effect profile, while also being capable of elevating serum anandamide concentrations. This increase in anandamide concentration by CBD is particularly noteworthy, for experiments have not only reported elevated anandamide levels in treatment naive and acute psychotic patients, but also CBD's prevention of anandamides' enzymatic degradation, and an inverse relationship between patients' anandamide concentrations and intensity of psychotic symptoms $[22,24,104-105]$. Subsequently the antipsychotic efficacy of CBD was assessed and compared with placebo treatment, so as to test whether CBD (600mg/day) 
administration could attenuate antipsychotic symptoms by modulation of serum anandamide levels [103]. Each drug was administered for 14 days on a double-blind basis prior to crossover; 11 subjects dropped out, one of which was in the CBD treatment group, leaving 18 treated patients after 28 days. Significant improvements were reported following the first 14 days of CBD treatment, given that favourable- though not significant- positive and negative syndrome scale (PANSS) scores(compared with baseline) were reported.

Following the success of their previous study [103], the team went on to conduct a doubleblind clinical trial on a cohort of 42 schizophrenic patients comparing CBD and amisulpride treatment over 4 weeks [106]. It was reported that doses of CBD amounting to $800 \mathrm{mg} / \mathrm{day}$ not only exhibited a markedly superior side-effect profile to amisulpride, but also equal antipsychotic efficacy. It was also stated that CBD treatment inhibited fatty acid amide hydrolase (FAAH) - the enzyme responsible for the degradation of anandamide- in rat brains at a median concentration of $8.6 \pm 0.2 \mu \mathrm{m}$. This inhibition of FAAH- and as such anandamide's enzymatic break-down- was confirmed in the test subjects, with CBD treated individuals having exhibited higher serum anandamide concentrations compared to amisulpride treatment. This in turn was shown to result in notable clinical improvements, in part owing to the aforementioned statistically significant inverse correlation between the patients' serum anandamide concentrations and psychotic symptoms, which as such provides compelling evidence of CBD's antipsychotic efficacy, as well as a clue as to its potential mechanism of action $[24,104]$.

\section{CBD'S ANTIPSYCHOTIC EFFICACY UNDER NEUROIMAGING SCRUTINY}

Following years of speculations regarding THC's purported psychotocatalytic and the largely positive- yet still inconclusive- literature detailing experiments into the antipsychotic efficacy of $\mathrm{CBD}$, studies utilising functional magnetic resonance imaging (fMRI) started to emerge in the past 5 years.

The purpose of the emerging studies was to analyse the behaviour of subjects during tasks and their responses to stimuli following the administration of CBD $(600 \mathrm{mg})$, or THC $(10 \mathrm{mg})$, or placebo, and how these correlated with the regional brain activation of a 15 healthy man cohort; although the paradigm largely remains fixed throughout the studies, a small number of the studies are slightly different, in which case it is explicitly stated. Winton-Brown's paper [107] explains the rationale behind the fixed oral dosages of THC and CBD utilised for the fMRI studies, stating that previous research has reported that they induce an effect on the regional brain function while avoiding the induction of severe detrimental psychiatric, physical, and toxic effects. Despite admitting that a larger cohort may provide greater insight into the effects that THC and CBD have on regional brain activation, Borgwardt [108] and some of the subsequent studies ward off criticism of unsuitably small cohorts, citing logistical difficulties, and Friston's [109] analysis into what cohort size constitutes a study, as justification [110].

The association between the behaviour and the neuroimaging results would as such allow for inference as to the place, and mechanism of action behind CBD and THC (if CBD really attenuates the psychotic symptoms induced by THC administration, then are the antagonistic effects observed in the same brain regions?). With the exception of the tasks undertaken by the subjects all of the neuroimaging experiments that have emerged share a common paradigm design (double-blind randomized, cross-over, fMRI, CBD vs THC vs placebo paradigm) $[65,82,107-108,110-111]$. 
Borgwardt [108] lead the first 3-session double-blind pseudo-randomized cross-over fMRI study to analyse the effect of THC, CBD, or placebo treatment on the behaviour and associated regional brain activation in healthy individuals. The cohort's performance in a motor inhibition related (Go/No-Go) task was scrutinized, alongside their blood oxygen level dependency (BOLD) response. Although there were higher left/right errors following THC and CBD treatment, there was no significant inhibition error or reaction time differences found to exist between the 3 treatments- the authors postulate that this lack of drug effect on task inhibition may possibly be down to a ceiling effect which manifests as a result of the utilised task paradigm having reasonably long interstimulus intervals (ISI). The fMRI data revealed that- when compared with the placebo treatment- THC administration resulted in activation of the right inferior frontal and anterior cingulate gyrus, which, as predicted by the authors [108], suggests that THC modulated activity in brain regions responsible for mediating response inhibition and motor control. In contrast, CBD administration induced deactivation of the left temporal cortex and insula, which aren't usually association with mediation of response inhibition; the authors are quick to indicate that the effects on regional brain activation bore no relation to changes in the individual's psychotic symptoms, intoxication, sedation, or anxiety [108].

The second neuroimaging study which utilise the BOLD fMRI paradigm to emerge was Fusar-Poli's [110], who set out to assess the regional brain activation and autonomic anxiety-related electrodermal activity (skin conductance response [SCR]; though objective and subjective gauges were utilised in conjunction with this paradigm) of 15 healthy subjects during emotional processing of fearful faces while under the effects of either THC, CBD, or placebo. As aforementioned, this experiment was of a double-blind, randomized, cross-over design. The results showed activation of frontal and parietal areas subsequent to THC administration, which was accompanied by an increase in sedation, psychotic symptoms, intoxication, and anxiety (SCR fluctuations) [110]. On the other hand CBD administrations lead to a suppression of the BOLD signal in the amygdala, and the anterior \& posterior cingulate cortex of the subjects, which was confirmed by single-photon emission tomography (PET). As explained by the authors, the suppression of a BOLD signal in these limbic and paralimbic regions were concurrent with- and may help explain- the anxiolytic effect and suppression of SCR fluctuations observed following CBD administration [110].

Since preceding studies have suggested that anxiogenic situations may result in the release of anandamide from the amygdala, Fusar-Poli [110] reasons that anandamide may in turn regulate emotional states and anxiety by modulating the output of the amygdala to other brain regions [112-114]. Since CBD has been shown to reduce the enzymatic degradation of anandamide, the hypothesised augmentation of anandamide concentrations by CBD is as such implicated as a potential mechanism from which CBD's antipsychotic pharmacology arises [22,24,105-106].

In a pioneering study Bhattacharyya [65] firstly sought to elucidate the opposing effects of $\mathrm{THC}$ and $\mathrm{CBD}$ on regional brain activation, before going on to investigate the attenuating effect CBD pre-treatment has on THC-induced acute psychotic symptoms. The first paradigm was tested on 15 men during the viewing of fearful faces, as well as performance of a verbal memory, response inhibition, and sensory processing task on 3 separate pseudorandomized occasions. THC and CBD were found to induce opposing regional brain activation patterns relative to placebo in the striatum, hippocampus, amygdala, superior temporal cortex, and occipital cortex (during the verbal recall, response inhibition, viewing of fearful faces, speech listening, and visual processing tasks, respectively). The second part of the study (pseudo-randomized, double-blind, repeated measures, within- 
subject design) utilised 6 healthy volunteers on 2 separate sessions, in which CBD $(5 \mathrm{mg})$, or placebo, was administered intravenously (IV) over 5 minutes, prior to a 5 minute administration of IV THC $(1.25 \mathrm{mg})$ - the manifest positive psychotic symptoms being measured in accordance with PANSS at baseline, 30, and 90 minutes post-THC. Of the 6 subjects, 3 experienced psychotic symptoms following THC administration subsequent to placebo pre-treatment, and these 3 subjects all exhibited an attenuation of these manifest symptoms 30 minutes after CBD pre-treatment \& THC administration, as reflected by a decrease in their mean PANSS scores. In all the participants' PANSS scores shown that THC-induced psychotic symptoms were significantly lower following CBD pre-treatment, compared to placebo pre-treatment. As such, this second experiment provides not only strong evidence in support of the postulated neuroleptic efficacy of CBD (given its attenuation of THC-induced psychotic symptoms), but also support for the hypothesis that the antagonistic action of the two cannabinoids on regional brain activation may be behind CBD's antipsychotic effect. Bhattacharyya [65] also goes so far as to postulate potential pharmacodynamic mechanisms underlying its pharmacological profile. These postulations include the aforementioned anandamide hydrolysis and reuptake inhibition hypothesis, as well as $\mathrm{CB} 1$ receptor antagonism (for the opposing effects of $\mathrm{THC}$ and $\mathrm{CBD}$ on brain regions are consistent with the distribution of $\mathrm{CB} 1$ receptors).

Winton-Brown [107] set out to further the line of inquiry generated by the aforementioned neuroimaging studies by assessing the effects of THC $(10 \mathrm{mg})$ and CBD $(600 \mathrm{mg})$ on sensory cortices. This was achieved by $\mathrm{fMRI}$ scans during auditory processing (i.e., gauged during passive listening to words by the volunteer) and visual processing (i.e., evaluated during the viewing of a "radial visual checkerboard in alternating blocks"). The experiment was carried out on 14 volunteers on 3 separate occasions in a double-blinded pseudo-randomized crossover designed study, with their anxiety and psychotic phenomena (PANSS) having been measured prior to, after, and post, fMRI scanning. While CBD was found to induce no notable symptomatic effects, THC resulted in the increase in the subject's anxiety, intoxication, and positive psychotic symptoms.

During the visual processing paradigm THC both increased (in the lingual, fusiform, and middle occipital gyri) and decreased (in areas activated under placebo, primarily in the extrastriate visual cortex) activation in different visual areas relative to placebo [107]. The increase in activation across the visual cortex following THC administration, relative to placebo, was found to be correlated and concomitant to the increase in psychotic symptoms, and as such PANSS scores- though this trend was found to be statistically insignificant. In addition, CBD administration solely increased regional brain activation relative to placebo in areas such as the right occipital lobe, cuneus, middle \& inferior occipital gyri, and the lingual gyrus [107]. When the effects of THC and CBD administration were contrasted a mixed effect on the cerebellum was found, while THC was found to activate the left lingual and middle occipital gyri, and attenuate activation of widespread occipital regions, bilaterally, relative to CBD.

Furthermore, the auditory test paradigm revealed that THC administration resulted in a decrease in the activation of the bilateral temporal cortices (relative to placebo), while CBD promoted activation in the right temporal cortex [107]. When contrasted, the two substances exerted opposing effects- attenuative from THC, excitatory from CBD- on the right posterior superior temportal gyrus (the right-sided Wernicke's area homolog) during auditory processing, which just so happens to correlate with the effect THC had on manifesting psychotic symptoms. The attenuation of the right temporal cluster induced by THC administration, relative to placebo, was found to be concomitant and correlated to the 
subjects' increase in psychotic symptoms as measured by their significant PANSS score increases [107]. As such, this study affirms the belief that THC and CBD have distinct effects- at times in opposing directions- on regional brain activation patterns. Thus, given the statistically significant increase in psychotic symptoms that was observed following THC administration during the auditory test paradigm, indirect support can be inferred to the postulated antipsychotic efficacy of CBD, especially given the study's crucial scrutiny of how the induction of psychotic symptoms correlate with the effects of THC and CBD on sensory cortices.

A year following the publication of Winton-Brown's [107] positive findings, Bhattacharyya's [115] study emerged, which sought to investigate the effects of THC and CBD on regional brain function during attentional salience processing task. Salience has been a pertinent gauge of psychotic symptoms since evidence emerged that the elevation of dopaminergic activity in the striatum has become associated with increased salience attribution to insignificant stimuli; this became affirmed by studies ascribing abnormal salience and striatal activation to delusions and schizophrenic patients, respectively [115-119]. Following the administration of THC, CBD, or placebo, the 15 subjects were asked to focus their attention on the detection of an infrequent (oddball) stimulus within a sequence of frequent (standard) stimuli, allowing for assessment of their visuo-spatial attention allocation to salience. The study hypothesised that THC administration would result in a disruption of the subject's salience processing, leading to swifter responses to standard stimuli (relative to oddball stimuli), owing to altered stimulation of the prefrontal cortex, medial temporal cortex, and striatum- brain regions which had previously been implicated with the processing of salience by earlier studies which utilised similar paradigms [114-115]. While exhibiting augmentative effects in the prefrontal cortex, the administration of THC also lead to suppressed activation of the hippocampus and dorsal striatum. The suppressive effect of THC on the dorsal striatum was reported to be negatively correlated with both the severity of the cohort's psychotic symptoms and the effect on their salience response latency, which was disrupted in accordance with the aforementioned hypothesis. Furthermore, as predicted, CBD resulted in an opposing task-related activation pattern to THC, when compared to placebo; augmentation of striatal and hippocampal activation was reported in conjunction with inhibition of prefrontal activation. Given that CBD positively influenced salience processing, as well as having increased the subjects' response latency speed for oddball stimuli relative to standard stimuli, Bhattacharyya's [115] research group postulated that CBD may have, given consistent evident supporting the notion that CBD has both behavioural and neurophysiological effects opposing THC's, potential for therapeutic use as an antipsychotic.

\subsection{Implications of Neuroimaging Studies}

As such, the detailed fMRI studies looking into the effects of both THC and CBD, relative to placebo, on regional brain activation revealed some integral indications as to the manner in which, and crucially the potential mechanism with which CBD exerts its antipsychotic effect. The fMRI data showed that CBD and THC had opposing effects, relative to placebo, in a number of cerebral areas, including the amygdala, anterior cingulated cortex, cerebellum, middle occipital gyrus, right posterior superior temporal gyrus, parahippocampal gyrus, prefrontal cortex, and the striatum [65,82,107-108,110,115]

The identification of specific brain regions in which CBD and THC exert their opposing effect is fundamental to the progression of our understanding of both the pharmacodynamics of $\mathrm{CBD}$, and pathophysiology of schizophrenia, hence the importance of these neuroimaging studies. The studies of Bhattacharyya [114] and Winton-Brown [107] report, for example, 
that CBD was capable of opposing the reduction in activation induced by THC in the striatum and right temporal lobe of the participants during paired associate learning tasks and auditory processing, respectively. In these two studies the reduction in regional brain activation by THC was reported to be correlated with an increase in the severity of exhibited psychotic symptoms- an effect which was not manifest following CBD administration. As such we are able to postulate that the ventral striatum is a brain region involved in CBD's pharmacodynamics and resultant neuroleptic efficacy, a theory which is supported by studies which implicate the ventral striatum with the pathogenesis of schizophrenia $[65,120]$.

Similarly, the temporal lobe- the right one of which is considered important in the comprehension of metaphorical language and perception of subordinate meaning in ambiguous words- has been implicated with psychotic disorders, including auditory hallucinations [121-123]. Since schizophrenic patients have been reported to show an impairment in their comprehension of figurative language, Bhattacharyya's [115] study becomes all the more pertinent for reporting that a reduction in the activation of the right temporal lobe- and increase in psychotic symptom severity- followed THC administration during auditory processing [82,124].Thus we can again postulate that- because of THC's reductive effect on the regional brain activation, which is concurrent with an increase in psychotic symptoms- the right temporal lobe can be considered an area associated with the neuroleptic effects CBD, given this latter substance's converse effect on brain activation and psychotic symptom severity.

As such it can be concluded that the neuroimaging studies strongly suggest that the ventral striatum and temporal lobe, which are areas commonly associated with psychosis, are two primary brain regions associated with the effects of CBD, which in turn manifests its antipsychotic pharmacology, at least in relation to the psychotomimetic effects of THC [82].

\section{RESULTS OF DETAILED INVESTIGATIONS AND SIGNIFICANCE TO BRITISH CANNABIS SMOKERS}

It is evident that the literature on the antipsychotic efficacy of cannabidiol possesses some incongruities and is in need of further clarifying research, in part owing to the lack of explicit understanding as to its pharmacodynamics, though it does for the most part appear to support the notion that CBD exhibits a pharmacological profile akin to that of atypical antipsychotics.

The major repercussion of this body of evidence is that it brings Frisher's [33] aforementioned study (on page 4)and its assertions under enquiry, for the study scrutinised the incidences of schizophrenia and psychoses in the years 1996-2005 based upon 3 aforementioned assertions, and yet found largely torpid and at times declining incidences of psychoses. However, since studies [11,34], have reported that the U.K Cannabis street market primarily constituted of hashish- which has been reported to contain higher concentrations of cannabidiol- prior to c.2000 (Table 1), then it can be proposed that Frisher's [33] years of focus was at fault. As such there is the potential for unacknowledged latent repercussions to the U.K's Cannabis smokers, for it would manifest 20 years on from the transition into a sinsemilla (High THC, low CBD) dominated street market (c.2000), assuming Frisher's [33] $1^{\text {st }}$ and $2^{\text {nd }}$ assertions are sound. Given this prospect it can be strongly argued that a greater impetus on both exogenous and endogenous cannabinoid research is necessary, so as to clarify understanding of both CBD's pharmacological efficacy 
and our presently limited comprehension of its pharmacodynamics, the current understanding of which will be briefly outlined subsequently.

Furthermore there is arguable a need for more research to be done into the role of the endocannabinoid system is necessary so as to further our understanding of neurophysiology, and our comprehension of psychiatric disorders, neuropsychopharmacology, and CBD's pharmacodynamics.

Bhattacharyya [65] uses the preliminary evidence of Zuardi [72] as a foundation to posit the possibility that cannabidiol only exhibits antipsychotic potential in patients hitherto afflicted with psychosis- though, in light of the large body of evidence supporting the theory that it mitigates artificially-induced acute psychotic symptoms in subjects, we have grounds to refute this.

\section{POSTULATED PHARMACODYNAMICS BEHIND CBD'S ANTIPSYCHOTIC PHARMACOLOGY}

The literature has produced a wealth of speculations into the prospective pharmacokinetic mechanisms behind CBD and its resultant pharmacological properties as is partly to be expected, given the plethora of aforementioned therapeutic properties [15,27]. Thus, so as to elucidate the array of convoluted postulations, the prominent pharmacokinetic theories relating to of CBD's antipsychotic pharmacology will be subsequently collated from prominent fields of CBD research. Most of the studies investigating the mechanisms of CBD have been performed In Vitro, and as such their relevance to In Vivo effects are uncertain, as rightly pointed out by [82]. He goes on to compellingly justifies this exercise of caution by calling attention to the contradiction that arises when CBD is hypothesised to lower the endocannabinoid system's activity by antagonisism of CB1 \& CB2 receptor agonists, while also being speculated to be capable of inhibiting the metabolism and re-uptake of the endocannabinoid anandamide, which would conversely result in an increase, rather than decrease, of the endocannabinoid system's activity.

\subsection{Endocannabinoid System Interaction: Cannabinoid CB1 \& CB2 Receptor (CB1/2R) Activity}

As previously stated, CBD was initially believed to have lacked pharmacological properties due to early research reporting a lack of $\mathrm{CB}$ receptor binding affinity. CBD has subsequently been shown to exhibit $\mathrm{CB}$ receptor affinity in the micromolar range, comparative to the low nanomolar requirement for THC; molecular reconfiguration of CBD's stereochemistry- from its $(-)$ to $(+)$ enantiomer- has been shown to enhance receptor affinity $[15,125]$. More recent studies have surprisingly reported that $\mathrm{CBD}$ exhibits antagonistic interaction with both $\mathrm{CB} 1$ and CB2 receptor at lower than expected concentrations. The research showed that CBD had an unexpectedly high antagonistic capacity to the agonists of mouse whole-brain cells (CB1 receptors) and Chinese hamster ovary cell membranes which were transfected with human $\mathrm{CB} 2$ receptors; they reported ostensible $\mathrm{K}_{\mathrm{B}}$ values in the low nanomolar range [2930]. Furthermore, Pertwee [15] has speculated that the unexpected nature of CBD's antagonistic action raises the prospect of this antagonism being of a non-competitive nature. Since Bhattacharyya's [65] study found that CBD-THC antagonism occurred in regional brain areas which were correlate to $\mathrm{CB} 1$ receptor distribution-and given that $\mathrm{THC}$ and other exogenous CB1R agonists have been shown to both induce psychotic symptoms in healthy individuals and exacerbation of psychotic symptoms in schizophrenic patients- one may 
postulate that CBD's antipsychotic efficacy is owed to its CB1R antagonism [82,126-128]. Having said this, a large number of schizophrenic patients have been used to test the antipsychotic effects gained from a CB1R antagonist (SR141716), which yielded no positive support [129].

\subsection{Endocannabinoid System Interaction: Inhibition of Anandamide Enzymatic Hydrolysis and Reuptake}

Anandamide levels have been found to be up to eight-fold greater in treatment-naive and psychiatric patients who are subject to treatment with atypical antipsychotics, whereas healthy individuals, patient with dementia, and patients treated with typical antipsychotics did not exhibit this elevation [22,24,82,104-106,130]. The Studies that have reported this have also proposed that this elevation in anandamide- given its inverse correlation with psychotic symptoms- is a compensatory adaption to the state of psychosis, inferring that it potentially acts as an endogenous antipsychotic, released by the body in an attempt to attenuate psychosis onset. This hypothesis is supported by Koethe's [131] study, which reported an increased in time taken to reach a state of frank psychosis in patients with elevated anandamide concentrations. Seeing as CBD has been shown to prevent anandamide's enzymatic degradation by fatty acid amide hydrolase (FAAH), while also preventing its reuptake, it could be reasoned that this- in conjunction with research reporting an inverse relationship between anandamide serum concentration and psychotic symptomsis a potential mechanism of action behind CBD's antipsychotic efficacy [22,24,103,105-106]. Cannabidiol's capacity to prevent degradation and uptake of anandamide was found to be augmented by stereochemistry reconfiguration to its $(+)$ enantiomer $[15,125]$.

In his literature review Zuardi [82] rightly tackles the major uncertainty which accompanies the postulation of anandamide playing a role in CBD's neuroleptic effect- that of the neuronal circuitry involved. His postulation is centred on the notion of anandamide-related endocannabinoid regulation of the major brain areas understood to be associated with the pathophysiology of schizophrenia, namely the ventral tegmental area, nucleus accumbens, ventral pallidum, mediodorsal thalamic nucleus and the prefrontal cortex [132]. Zuardi's [82] hypothesised neuronal framework which drives anandamide's role in manifesting CBDinduced neuroleptic effects is depicted in the article [82], and is explained as such:

Supersensitive dopaminergic receptor response in the nucleus accumbens of rodents with artificially-induced psychosis have been reported, which studies have shown would results in the inhibition of both the local medium-spiny GABAergicneurons (which are inhibited by the activation of dopamine D2-like receptors [133-134], and constitute $~ 95 \%$ of the nucleus accumbens' neurones), and the medium-spiny associated GABA releasing terminal in the ventral pallidum [82,133-136]. As such, Zuardi [82] hypothesises that the release of dopamine by projections from the ventral tegmental area (VTA) in the nucleus accumbens could alleviate the inhibition of GABAergic neurones in the ventral pallidum, and as such result in elevated action of the pallidum-mediodorsal thalamus. Thus there would be a resultant reduction in the glutamate release from the pallidum-mediodorsal thalamus to the prefrontal cortex, which would manifest in the form of impairment to locomotor activity and working memory- symptoms indicative of psychosis [137].

Zuardi [82] goes on to suggests that endocannabinoids could regulate this system, for the endocannabinoid system synthesises anandamide and 2-AG on post-synaptic clefts and acting pre-synaptic terminals as part of its role as a negatively-regulating retrograde 
signalling system [138]. GABA and glutamate neurotransmitters are under particular regulatory scrutiny at the hands of the endocannabinoid system, and since CB1 receptors in the basal ganglia are located on GABAergic axon terminals to a greater degree than glutamatergic ones, one could infer that CBD-induced elevations in anandamide concentrations may attenuate the undesirable function of the aforementioned system by inhibiting GABA release from the neurones of the ventral pallidum [82,138-139].

\subsection{Endocannabinoid System Interaction: GPR55 Receptor}

A developing field of interest in cannabinoid research is the discovery of novel cannabinoid receptors, with a breakthrough in the form of successful sequencing and cloning of GPR55a proposed novel human, mouse, and rat cannabinoid receptor- having materialized [140141]. The receptor exhibits a similar function and agonistic profile to existing CB receptors, and is activated by established endogenous and exogenous CB receptor agonists like anandamide and THC, though it is surprisingly antagonised by CBD at lower concentrations than that which is considered as required to displace CB1 and CB2 receptor agonists [141].

\subsection{The Anti-inflammatory Action of CBD; Vanilloid and Adenosine Signalling Pathway Interaction}

CBD has also been found to be capable of activating Transient Receptor Vanilloid-1 (TRV1) receptors [22,139], which are expressed in brain areas such as the prefrontal cortex, amygdala, and hippocampus- areas which have been implicated with states of psychosis [142]. The endocannabinoid Anandamide is the most studied putative endovanilloid (EV) and TRV1R agonist $[82,143]$. The agonism of pre-synaptic TRV1R- unlike the activation of CB1 receptors- results in the facilitation of glutamate release [144]. The role of TRV1R in CBD's antipsychotic efficacy is supported by two aforementioned studies; Guimarães [85] reported an increase in neuronal activation in the medial prefrontal cortex and limbic-related nucleus accumbens of rats (as measured by cFos immunohistochemistry) following antipsychotic doses of CBD (120mg/kg), while Long [82] has reported that CBD's attenuation of MK-801(a non-competitive glutamate antagonist)-induced PPI disruption in rats was prevented by TRPV1 antagonists [82].

CBD has also been found to have a mechanism of action analogous to both the natural (capsaicin) and synthetic VR1 agonists, though to a weaker degree than the former. The Vanilloid VR1 receptor is involved in the mechanism of inflammatory hyperalgesia, though stimulation by its natural agonists, capsaicin, results in express paradoxical antiinflammatory and analgesic effects (owing to VR1 receptor desensitization) in response to nociceptive stimuli, and by causing depletion of sensory vasoactive neuropeptides $[22,145]$.

Further explanation for cannabidiol's putative anti-inflammatory activity can be inferred by binding studies which report that CBD binds to equilibrative nucleoside transporters; other studies report a decrease in $[3 \mathrm{H}]$ adenosine uptake in the macrophages and microglia of murine models $[9,146]$.

It's possible that CBD's potent anti-inflammatory and anti-oxidant/neuroprotective action (detailed subsequently) is involved in its ostensible antipsychotic pharmacology, for it is thought that the anti-inflammatory and neuroprotective pharmacology of minocycline- a new broad-spectrum tetracycline antibiotic used as add-on schizophrenia treatment- may be behind its beneficial psychiatric therapeutic effects [9,76,147-148]. 


\subsection{Serotonin 5-HT1a Receptor Agonism}

Although little is known about the role the serotonergic system has to play in schizophrenia it is hoped that more information will come to light because of the discovery of Aripiprazole, a novel antipsychotic which exhibits partial 5-HT1a agonism in conjunction with its 5-HT2a and dopamine D2 receptor interaction; it is thought that its serotonergic action plays a role in its therapeutic benefit $[82,149]$.

Cannabidiol's anxiolytic and antidepressant effects have also been attributed to its agonistic relationship to human serotonin $1 \mathrm{a}(5-\mathrm{HT} 1 \mathrm{a})$ receptors [22,28,149-153]. Although it would be tempting to attribute CBD's anxiolytic effect to its neuroleptic properties, studies using rodent models have shown that the induction an anxiolytic effect $(5-20 \mathrm{mg} / \mathrm{kg})$ is far lower than the dosages necessary to induce antipsychotic effects $(60-120 \mathrm{mg} / \mathrm{kg})$; the former effect doseresponse curve is bell-shaped, rendering larger doses ineffective [74,154-155]. It was postulated that rat resistance to chronic cannabinoid effects on the $5-\mathrm{HT} 1 \mathrm{a}$ is due to the high basal density of this receptor in rats [66]; could the incongruities observed with CBD's antipsychotic efficacy during the human investigations trials also have emerged as a result of varying basal densities of certain receptor groups?

\subsection{Neurogenesis}

CBD has been shown to be capable of increasing neurogenesis in mice, in a CB1R mediated manner [156]. Since the discovery that schizophrenic patients exhibit impaired neurogenesis in the hippocampus postulations have emerged which suggest that altered neurogenesis may be the cause of the cognitive deficits, and potentially other symptoms, observed in schizophrenic patients [157,158]. As such, augmented neurogenesis may be one facet of CBD's action which gives rise to its relatively successful long-term antipsychotic efficacy in the clinical trials.

\subsection{Anti-oxidant Action}

CBD's ostensible antipsychotic pharmacology may be in part due to its anti-oxidant properties. Hampson [159] performed a study wherein it was discovered that CBD (and THC) prevents oxidative damage induced by hydrogen peroxide $\left(\mathrm{H}_{2} \mathrm{O}_{2}\right)$ equally or better than tocopherol (vitamin E) or ascorbate (vitamin $\mathrm{C}$ ), and as such may be behind the putative neuroprotective/antioxidant properties of cannabidiol [9]. Valvassori's [81] aforementioned study also asserts CBD's capacity to protect rats against oxidative stress, for it prevented dexamphetamine-induced damage in the hippocampus and striatum.

\subsection{Peroxisome Proliferator-Activated Receptors (PPARs) Activity}

Peroxisome proliferator-activated receptors (PPARs), which are expressed in the nervous system and classified into three sub types $(\alpha, \beta, \gamma)$, are part of the nuclear receptor family[160]. PPARs are ligand-activated transcription factors which fulfil important roles in lipid metabolism, hepatic peroximal enzyme expression, insulin sensitivity and glucose homeostasis, which arise as a result of their regulating effect on gene expression subsequent to binding with sequence-specific promoter elements on target genes [161-162]. Although the mechanism behind cannabinoid-PPAR interaction is unclear, a large number of cannabinoids have been found to act as PPAR ligands [28,160,163-164]. While anandamide has been found to interact with both PPAR- $\alpha$ and PPAR-y receptors, cannabidiol and THC 
were found to only interact with PPAR-y. Neuroprotective, antioxidant effects have been associated with these pathways $[28,160,162,165]$. THC has been found to exhibit a direct neuroprotective action in a human cell culture model of Parkinson's disease through PPAR- $Y$ activity, whilst CBD did not [166]. On the other hand, one study showed that CBD increased hippocampal neurogenesis and Amyloid Beta $(A \beta)$-induced neuroinflammation, while another found that CBD attenuated endoplasmic reticulum (ER) stress in oligodendrocyte progenitor cells by lowering the concentration of ER apoptotic effectors [167-168]. These neuroprotective, antioxidant, effects may, as aforementioned in the previous section, be partially responsible for CBD's (and anandamide's, as a result of FAAH's inhibition by CBD) antipsychotic effects.

For a highly detailed account of the ostensible pharmacodynamics which may be involved in CBD's antipsychotic properties the reader is advised to consult the papers of Pertwee [15] and Izzo [28].

\section{CONCLUSION}

To conclude, for nigh on 50 years there has been gradually emergent interest pertaining to the abundance of CBD's pharmaceutical effects (see [15] and [27]), which hold immense therapeutic interest and potential utility. Although there is still a wealth of conjecture as to the true extent of its pharmacological efficacy and pharmacodynamics, the lack of comprehensive understanding ought to fuel the impetus for further studies into CBD and cannabinoids generally, in light of the therapeutic potential this once-considered inert compound seemingly exhibits. Furthermore, our lack of understanding regarding the crucial role of the endocannabinoid system, and its role in psychiatric disorders, means that investigations tackling this topic will possess ample heuristic value, given the implications the resultant knowledge would have not only on our general understanding of neurophysiology, but also our comprehension of neuropharmacology and psychiatric disorders.

The question of CBD's antipsychotic potential is of particular significance given the aforementioned decline of its concentration in U.K. street market Cannabis as of c.2000, which was juxtaposed with a significant increase in availability of Cannabis cultivars with substantially higher mean concentrations of the ostensibly psychotocatalytic THC. Were CBD's antipsychotic efficacy to be affirmed and established, then, as aforementioned, this development has the potential for considerable anthropological ramifications in the form of substantial increases in psychosis manifestations and diagnoses in the U.K. If confidence was to be placed on research which suggests that the typical precipitation time of psychosis is 20 years subsequent to Cannabis use, then this spike would be expected to occur between the years 2020-2030.

The research literature largely affirmed the hypothesis that CBD possesses antipsychotic efficacy akin to atypical antipsychotics, the significance of which is all the more potent since it may have particular advantages in the potential treatment of Parkinson's disease patients with psychosis, given CBD's comparatively low side and toxiceffects induction.

Significant hypotheses for the mechanisms behind CBD's antipsychotic efficacy include cannabinoid CB receptor antagonism, and inhibition of anandamide hydrolysis \& reuptake, amongst others. Given the endocannabinoid system's modulation, and consequent interrelation with other neurological pathways (including glutamate, GABA, and serotonin, all of which have been independently implicated with psychosis), a potentially fundamental discovery pertaining to the aetiology and pathophysiology of psychiatric disorders could 
result from further investigation into the endocannabinoid system as a whole, as well as the effect of exogenous cannabinoid exposure.

Research into cannabinoids and the cannabinoid system is still very much a developing field. The encouraging findings detailed, together with our limited understanding of CBD's pharmacodynamics and resultant therapeutic efficacy, should instil a greater impetus for the scientific community to clarify our comprehension of this field, particularly given the wide prevalence, and immense pharmacological pharmacological potential, of Cannabis- one of the worlds' most ancient and utilised medicinal \& recreational drug.

\section{CONSENT}

Not applicable.

\section{ETHICAL APPROVAL}

Not applicable.

\section{COMPETING INTERESTS}

Authors have declared that no competing interests exist.

\section{REFERENCES}

1. Merlin MD. Archaeological evidence for the tradition of psychoactive plant use in the old world. Econ Bot. 2003;57(3):295-323.

2. $\mathrm{Li} \mathrm{HL}$. The origin \& Use of Cannabis in Eastern Asia: Their Linguistic-Cultural Implications Cannabis\& Culture, 1st Edition, Mouton \& CO. 1975;51-53.

3. Oomah DB. Characteristics of hemp (Cannabis sativa L) seed oil. Food Chem. 2002;76:33-43.

4. Mikuriya TH. Marijuana in Medicine: Past, Present and Future. California Medicine. 1969;110(1):34-44.

5. O'Shaughnessy WB. On the Preparations of the Indian Hemp, or Gunjah: Cannabis Indica; Their Effects on the Animal System in Health, and their Utility in the Treatment of Tetanus and other Convulsive Diseases. Prov Med J Retrosp Med Sci. 1843;5(123):363-369.

6. Zuardi AW, Crippa JAS, Hallak JEC, Moreira FA, Guimarães FS. Cannabidiol, a Cannabis sativa constituent, as an antipsychotic drug. $\mathrm{Br} \mathrm{J}$ Med Biol Res. 2006a;39(4):421-429.

7. Bardi GB. Taxonomy \& Morphology of Uncultivated Hemp (Cannabis Sativa L) as Weed in Hungary. Acta Botanica Hungarica. 2002;44:31-47.

8. Amar MB. Cannabinoids in medicine: A review of their therapeutic potential. $J$ Ethnopharmacol. 2006;105:1-25.

9. Zuardi AW. Cannabidiol: from an inactive cannabinoid to a drug with wide spectrum of action Rev Bras Psiquiatr. 2008;30(3):271-280.

10. Morgan CJA, Curran HV. Effects of Cannabidiol on schizophrenia-like symptoms in people who use Cannabis. Br J Psychiatry. 2008;192:306-307.

11. Potter DJ. Potency of D9-THC and Other Cannabinoids in Cannabis in England in 2005: Implications for Psychoactivity and Pharmacology. J Forensic Sci. 2008;53:9094. 
12. Russo E, Guy GW. A tale of two cannabinoids: the therapeutic rationale for combining tethrahydrocannabinol and cannabidiol. Med Hypo. 2005a;66:234-246.

13. Fride E, Mechoulam R. Pharmacological activity of the cannabinoid receptor agonist, anandamide, a brain constituent. Eur J Pharmacol. 1993;231(2):313-314

14. Gaoni Y, Mechoulam R.Isolation, structure and partial synthesis of an active constituent of hashish.J Am Chem Soc. 1964;86:1646-1647.

15. Pertwee RG. The diverse $\mathrm{CB} 1$ and $\mathrm{CB} 2$ receptor pharmacology of three plant cannabinoids: $\Delta^{9}$-tetrahydrocannabinol, cannabidiol and $\Delta^{9}$-tetrahydrocannabivarin. $\mathrm{Br}$ J Pharmacol. 2008;153:199-215.

16. Ashton $\mathrm{CH}$, Moore PB. Endocannabinoid system dysfunction in mood and related disorders. Acta Psychiatr Scand. 2011;124(4):250-261.

17. Adams R, Hunt M, Clark JH. Structure of Cannabidiol, a Product Isolated from the Marihuana Extract of Minnesota Wild Hemp. J Am Chem Soc. 1940;62:196-200.

18. Mechoulam R, Shvo Y. Hashish-1. Structure of Cannabidiol. Tetrahedron. 1963;19(12):2073-2078.

19. Clarke CR, Watson DP. Botany of natural Cannabis medicines. In: Grotenhermen F, Russo E, Varon RN, (editors). Cannabis and cannabinoids: Pharmacology, Toxicology and Therapeutic PotentiaL New York: The Howard Interactive Healing Press. 2002;313.

20. Mechoulam R, Gaoni Y. The absolute configuration of delta-1 tetrahydrocannabinol, the major active constituent of hashish. Tetrahedron Letters. 1967;8(12):1109-1111.

21. Carlini EA, Santos M, Claussen U, Bieniek D, Korte F. Structure activity relationship of four tetrahydrocannabinols and the pharmacological activity of five semi-purified extracts of Cannabis sativa. Psychopharmacology. 1970;18:82-93.

22. Bisogno T, Hanus L, De Petrocellis L, Tchilibon S, Ponde DE, Brandi I, et al. Molecular targets for cannabidiol and its synthetic analogues: effect on vanilloid VR1 receptors and on the cellular uptake and enzymatic hydrolysis of anandamide. $\mathrm{Br} \mathrm{J}$ Pharmacol. 2001;134:845-852.

23. Mechoulam R, Parker LA, Gallily, R. Cannabidiol: An Overview of Some Pharmacological Aspects. J ClinJ Clin Pharmacol. 2002;42:11-19.

24. Giuffrida A, Leweke FM, Gerth CW, Schreiber D, Koethe D, Faulhaber J, et al. Cerebrospinal Anandamide Levels are elevated in Acute Schizophrenia and are Inversely Correlated with Psychotic Symptoms. Neuropsychopharmacol. 2004;29:2108-2114.

25. Malfait AM, Gallily R, Sumariwalla PF, Malik AS, Andreakos E., Mechoulam R, Feldmann M. The nonpsychoactive Cannabis constituent cannabidiol as an oral antiarthritic therapeutic in murine collagen-induced arthritis. Proc Natl Acad Sci USA. 2000;97:9561-9566.

26. Srivastava MD, Srivastava BJ, Brouhard B. Delta9 tetrahydrocannabinol and cannabidiol alter cytokine production by human immune cells. Immunopharmacol. 1998;40:179-185.

27. Izzo AA, Borrelli F, Capasso R, Di Marzo V, Mechoulam R. Non-psychotropic plant cannabinoids: new therapeutic opportunities from an ancient herb. Trends Pharmacol Sci. 2009;30(10):515-527

28. Campos AC, Guimarães FS. Invement of 5HT1A receptors in the anxiolytic-like effects of cannabidiol injected into the dorsolateral pariaqueductal gray of rats. Psychopharmacology (Berl). 2008;199:223-230.

29. Thomas A, Baillie GL, Phillips AM, Razdan RK, Ross RA, Pertwee RG. Cannabidiol displays unexpectedly high potency as an antagonist of $\mathrm{CB} 1$ and $\mathrm{CB} 2$ receptor agonists in vitro. Br J Pharmacol. 2007;150:613- 623. 
30. Petitet F, Jeantaud B, Reibaud M, Imperato A, Dubroeucq MC. Complex pharmacology of natural cannabinoids: evidence for partial agonist activity of delta-8tetrahydrocannabinol and antagonistic activity of cannabidiol on rat brain cannabinoid receptors. Life Sci. 1998;63:1-6.

31. Koethe D, Hoyer C, Leweke, FM. The endocannabinoid system as a target for modelling psychosis. Psychopharmacology. 2009a;206:551-561.

32. Moore THM, Zammit S, Lingford-Hughes A, Barnes TR, Jones PB, Burke M, Lewis G. Cannabis use and risk of psychotic or affective mental health outcomes: a systematic review. Lancet. 2007;370:319-328.

33. Frisher M, Crome I, Martino O, Croft P. Assessing the impact of Cannabis use on trends in diagnosed schizophrenia in the United Kingdom from 1996 to 2005. Schizophr Res. 2009;113:123-128.

34. Di Forti M, Morgan C, Dazzan P, Pariante C, Modelli V, Marques TR, et al. High potency Cannabis and the risk of psychosis. Br J Psychiatry. 2009;195:488-491.

35. Matsuda LA, Lolait SJ, Brownstein MJ, Young AC, Bonner TI. Structure of a cannabinoid receptor and functional expression of the cloned cDNA. Nature. 1990;346:561-564

36. Munro S, Thomas, KL, Abu-Shaar M. Molecular characterisatization of a peripheral receptor for cannabinoids. Nature. 1993;365:61-65.

37. Skaper SD, Buriani A, Dal Toso R, Petrelli L, Romanello S, Facci L, Leon A. The ALIAmide palmitoylethanolamide and cannabinoids, but not anandamide, are protective in a delayed postglutamate paradigm of excitotoxic death in cerebellar granule neurones. Proc Natl Acad Sci USA. 1996;93:3984-3989.

38. Van Sickle MD, Duncan M, Kingsley PJ, Mouihate A, Urbani P, Mackie K, et al. Identification and functional characterization of brainstem cannabinoid CB2 receptors. Science. 2005;310:329-332.

39. Wotherspoon G, Fox A, McIntyre P, Colley S, Bevan S, Winter J. Peripheral nerve injury induces cannabinoid receptor 2 protein expression in rat sensory neurones. Neurosci. 2005;135:235-245.

40. Gong JP, Onaivi ES, Ishiguro H, Liu QR, Tagliaferro PA, Brusco A, et al. Cannabinoid CB2 receptors: immunohistochemical localization in rat brain. Brain Res. 2006;1071:10-23.

41. Devane WA, Hanus L, Breuer A, Pertwee RG, Breuer A, Pertwee RG, Stevenson LA, et al. Isolation and structure of a brain constituent that binds to the cannabinoid receptor. Science. 1992;258:1946-1949.

42. Mechoulam R, Ben-Shabat S, Hanus L, Ligmusky M, Kaminski NE, Schatz AR, Gopher A, et al. Identification of an endogenous 2-monoglyceride, present in canine gut, that binds to cannabinoid receptors. Biochem Pharmacol. 1995;50:83-90.

43. Sugiura T, Kondo S, Sukagawa A, Nakane S, Shinoda A, Itoh K, et al. 2Arachidonoylglycerol: a possible endogenous cannabinoid receptor ligand in brain. Biochem Biophys Res Commun. 1995;215:89-97.

44. Howlett AC, Barth F, Bonner TI, Cabral G, Casellas P, Devane WA, Felder CC, et al International Union of PharmacologY XXVII Classification of cannabinoid receptors. Pharmacol Rev. 2002;54:161-202.

45. Di Marzo V, De Petrocellis L, Bisogno T. The biosynthesis, fate and pharmacological properties of endocannabinoids. In: Pertwee, RG (editor) Cannabinoids. Handbook of Experimental Pharmacology. 168 Springer-Verlag: Heidelberg. 2005;147-185.

46. Coulston CM, Perdices M, Henderson AF, Malhi GS. Cannabinoids for the treatment of schizophrenia? A balanced neurochemical framework for both adverse and therapeutic effects of Cannabis use. Schizophr Res Treat. 2001;2011:1-9. 
47. Fernández-Ruiz F, Hernández M, Ramose JA. Cannabinoid-dopamine Interaction in the Pathophysiology and Treatment of CNS Disorders. CNS Neurosci Ther. 2010;16(3):72-91.

48. Zavitsanou K, Wang H, Dalton VS, Nguyen, V Cannabinoid administration increases $5 \mathrm{HT} 1 \mathrm{~A}$ receptor binding and mRNA expression in the hippocampus of adult but not adolescent rats. Neurosci. 2010;169:315-324.

49. Hallack JEC, Dursun SM, Bosi DC, de Macedo LR, Machado-de-Sousa JP, Abrão J, et al. The interplay of cannabinoid and NMDA glutamate receptor systems in humans: Preliminary evidence of interactive effects of cannabidiol and ketamine in healthy human subjects. Prog Neuropsychopharmacol Biol Psychiatry. 2011;35:198-202.

50. Godino MC, Torres M, Sanchez-Prieto J. CB1 receptors diminish both $\mathrm{Ca}(2+)$ influx and glutamate release through two different mechanisms active in distinct populations of cerebrocortical nerve terminals. J Neurochem. 2007;101(6):14711-1482.

51. Neu A, Foldy C, Soltesz I. Postsynaptic origin of CB1-dependent tonic inhibition of GABA release at cholecystokinin-positive basket cell to pyramidal cell synapses in the CA1 region of the rat hippocampus. Journal of Physiology. 2007;578:233-247.

52. Beneyto M, Kristiansen LV, Oni-Orisan A, McCullumsmith RE, Meador-Woodruff JH. Abnormal glutamate receptor expression in the medial temporal lobe in schizophrenia and mood disorder. Neuropsychopharmacol. 2007;32:1888-1902.

53. Lewis DA, Pierri JN, Volk DW, Melchitzsky DS, Woo TU. Altered GABA neurotransmission and prefrontal cortical dysfunction in schizophrenia. Biol Psychiatry. 1999;46(5):616-626.

54. Abi-Dargham A. Do we still believe in the dopamine hypothesis? New data bring new evidence. Int J Neuropsychopharmacol. 2004;7:1-5.

55. Hernández ML, Berrendero F, Suarez I, Garca-Gil L, Cebeira M, Mackie K, et al. Cannabinoid CB1 receptors colocalize with tyrosine hyrdoxylase in cultured fetal mesencephalic neurones and their activation increases the levels of this enzyme. Brain Res. 2000;857:56-65.

56. Wenger T, Moldrich G, Furst S. Neuromorphological background of Cannabis addiction. Brain Res Bull. 2003;61:125-128.

57. French ED, Dillon K, Wu X. Cannabinoids excite dopamine neurones in the ventral tegmentum and the substantia nigra. Neuroreport. 1997;8:649-652.

58. Diana M, Melis M, Gessa GL. Increase in meso-prefrontal dopaminergic activity after stimulation of CB1 receptors by cannabinoids. Eur. J Neurosci. 1998;10:2825-2830.

59. El Khoury MA, Grogievski V, Gorgievski V, Moutsimili L, Giros B, Tzavara ET. Interaction between the cannabinoid and dopaminergic systems: Evidence from animal studies. Prog Neuropsychopharmacol Biol Psychiatry. 2012;38:36-50.

60. Lipska BK, Weinberger DR. To model a psychiatric disorder in animals: schizophrenia as a reality test. Neuropsychopharmacol. 2000;23(3):223-239

61. Coyle JT. Glutamate and schizophrenia: beyond the dopamine hypothesis. Cell Mol Neurobiol. 2006;26:365-384.

62. Carlini EA, Karniol IG, Renault PF, Schuster CR. Effects of marihuana in laboratory animals and in man. Br J Pharmacol. 1974;50(2):299-309.

63. Carlini EA, Santos M, Claussen U, Bieniek D, Korte F. Structure activity relationship of four tetrahydrocannabinols and the pharmacological activity of five semi-purified extracts of Cannabis sativa. Psychopharmacology. 1970;18:82-93.

64. Fairbairn JW, Pickens JT. Activity of Cannabis in relation to its delta-trans-tetrahydrocannabinol content. Br J Pharmacol. 1981;27(3):401-409. 
65. Bhattacharyya S, Morrison PD, Fusar-Poli P, Martin-Santos R, Borgwardt S, WintonBrown T, et al. Opposite Effects of Delta-9-Tetrahydrocannabinol and Cannabidiol on Human Brain Function and Psychopathology. Neuropsychopharmacol. 2010;35:764774.

66. Klein C, Karanges E, Spiro A, Wong A, Spencer J, Huynh T, et al. Cannabidiol potentiates $\Delta^{9}$-tetrahydrocannabidinol (THC) behavioural effects and alters THC pharmacodynamics during acute and chronic treatment in adolescent rats. Psychopharmacology. 2011;218:443-457.

67. Gardner D, Baldessarini RJ, Waraich P. Modern antipsychotic drugs: a critical overview. Can Med Assoc J. 2005;172(13):1703-1711.

68. Gururajan A, Taylor DA, Malone DT. Effects of cannabidiol in a MK-801-rodent model of aspects of Schizophrenia. Behav Brain Res. 2011;222:299-308.

69. Krystal JH, Karper LP, Seibyl JP, Freeman GK, Delaney R, Bremner JD, et al. Subanesthetic Effects of the Noncompetitive NMDA Antagonist, Ketamine, in Humans: Psychotomimetic, Perceptual, Cognitive, and Neuroendocrine responses. Arch Gen Psychiatry. 1994;51(3):199-214.

70. Thanvi BR, Lo TCN, Harsh DP. Psychosis in Parkinson's disease. Postgrad Med J. 2005;81:644-646.

71. Naimark D, Jackson E, Rockwell E, Jeste, DV. Psychotic symptoms in Parkinson's disease patients with dementia. J Am Geriatr Soc. 1996;44(3):296-299.

72. Zuardi AW, Shirakawa I, Finkelfarb E, Karniol IG. Action of cannabidiol on the anxiety and other effects produced by delta 9-THC in normal subjects. Psychopharmacology. $1982 ; 76(3): 245-250$.

73. Rottanburg D, Robins AH, Ben-Aire O, Teggin A, Elk R. Cannabis associated psychosis with hypomaniac features. Lancet. 1982;2:1364-1366.

74. Zuardi AW, Rodrigues JA, Cunha JM.Effects of cannabidiol in animal models predictive of antipsychotic activity. Psychopharmacology (Berl). 1991;104(2):260-264.

75. Moreira FA, Guimarães FS. Cannabidiol inhibits the hyperlocomotion induced by psychotomimetic drugs in mice. Eur J Pharmacol. 2005;512:199-205.

76. Crippa JAS, Zuardi AW, Hallak JEC. Therapeutic use of the cannabinoids in psychiatry. Rev Bras Psiquiatr. 2010;32:56-65.

77. Long LE, Malone DT, Taylor DA. Cannabidiol reverses MK-801-induced disruption of prepulse inhibition in mice. Neuropsychopharmacol. 2006;31(4):795-803.

78. Braff DL, Geyer MA, Swerdlow NR. Human studies of prepulse inhibition of startle: normal subjects, patient groups, and pharmacological studies. Psychopharmacology. 2001;156:234-258.

79. Ludewig K, Geyer MA, lenweider FX. Deficits in prepulse inhibition and habituation in never-medicated, first-episode schizophrenia. Biol Psychiatry. 2003;54:121-128.

80. Malone DT, Jongejan D, Taylor DA. Cannabidiol reverses the reduction in social interaction produced by low dose Delta(9)-tetrahydrocannabinol in rats. Pharmacol Biochem Behav. 2009;93(2):91-96.

81. Valvassori SS, Elias G, de Souza B, Petronilho F, Dal-Pizzol F, Kapczinski F, et al. Effects of cannabidiol on amphetamine-induced oxidative stress generation in an animal model of mania. J Psychopharmacology. 2009;25:274-280.

82. Zuardi AW, Crippa JAS, Hallak JEC, Bhattacharyya S, Atakan Z, Martin-Santos R, et al. A critical Review of the Antipsychotic Effects of cannabidiol: 30 years of a translational investigation. Curr Pharm Des. 2012;18(32):5131-5140.

83. Long LE, Chesworth R, Huang XF, McGregor IS, Arnold JC, Karl T. A Behavioural comparison of acute and chronic Delta9-tetrahydrocannabinol and cannabidiol in C57BL/6jArc mice. Int J Neuropsychopharmacol. 2010;13:861-876. 
84. Reid MJ, Bornheim LM. Cannabinoid-induced alterations in brain disposition of drugs of abuse. Biochem Pharmacol. 2001;61:1357-1367.

85. Guimarães VM, Zuardi AW, Del Bel E, Guimarães, FS. Cannabidiol increases Fos expression in the nucleus accumbens but not in the dorsal striatum. Life Sci. 2004;75(5):633-638.

86. Almeida V, Levin R, Peres FF, Niigaki ST, Calzavara MB, Zuardi AW, et al. Cannabidiol exhibits anxiolytic but not antipsychotic property evaluated in the social interaction test. Prog. Neuropsychopharmacol Biol. Psychiatry. 2013;41:30-35.

87. Gururajan A, Taylor DA, Malone DT. Cannabidiol and clozapine reverse MK-801induced deficits in social interaction and hyperactivity in Sprague-Dawley Rats. J Psychopharmacology. 2012;26(10):1317-1332.

88. Long LE, Chesworth R, Huang XF, Wong A, Spiro A, McGregor IS, et al. Distinct Neurobehavioural effects of cannabidiol in transmembrane domain Neuregulin 1 mutant mice. PLoS One. 2012;7(4). Dol: e34129. http://dXdolorg/10.1371/journaLpone.0034129.

89. Calzavara MB, Levin R, Medrano WA, Almeida V, Sampaio AP, Barone LC, et al. Effects of antipsychotics and amphetamine on social behaviors in spontaneously hypertensive rats. Behav Brain Res. 2011;255:15-32.

90. Cunha J, Carlini EA, Pereira AE, Ramos OL, Pimentel G, Gagliardi R, et al. Chronic administration of cannabidiol to healthy unteers and epileptic patients. Pharmacology. 1980;21:175-185.

91. Consroe P, Laguna J, Allender J, Snider S, Stern L, Sandyk R, et al. Controlled clinical trial of cannabidiol in Huntington's disease. Pharmacol Biochem Behav. 1991;40:701708.

92. Zuardi AW, Morais SL, Guimarães FS, Mechoulam R. Antipsychotic effect of cannabidiol. J Clin Psychiatry. 1995;56(10):485-486

93. Bergamaschi MM, Queiroz RHC, Zuardi AW, Crippa JAS. Safety and side effects of cannabidiol, a Cannabis sativa constituent. Curr Drug Saf; 2011;6:237-249.

94. Schneider U, Borsutzsky M, Seifert J, Leweke FM, Huber TJ, Rollnik JD, et al. Reduced binocular depth inversion in schizophrenic patients. Schizophr Res. 2002;53:101-108.

95. Leweke FM, Schneider U, Radwan M, Schmidt E, Emrich HM. Different effects of nabilone and cannabidiol on binocular depth inversion in man. Pharmacol Biochem Behav. 2000;66:175-181.

96. Morgan CJA, Schafer G, Freeman TP, Curran VH. Impact of cannabidiol on the acute and psychotomimetic effects of smoked Cannabis: naturalistic study. $\mathrm{Br} \mathrm{J}$ Psychiatry. 2010;197:285-290.

97. Bech P, Kastrup M, Rafaelsen OK. Mini-compendium of rating scales for states of anxiety depression mania schizophrenia with corresponding DSM-III syndromes. Acta Psychiatr Scand Supp. 1986;326:1-37.

98. Bremner JD, Krystal JH, Putnam FW, Southwick SM, Marmar C, Charney DS, et al. Measurement of dissociative states with the Clinician-Administered Dissociative States Scale (CADSS). J. Trauma. Stress. 1998;11:125-136.

99. Schubart CD, Sommer IEC, van Gastel WW, Goetgebuer RL, Kahn RS, Boks MPM. Cannabis with high cannabidiol content is associated with fewer psychotic experiences. Schizophr Res. 2011;130:216-221.

100. Zuardi AW, Hallak JE, Dursun SM, Morais SL, Sanches RF, Musty RE, et al. Cannabidiol Monotherapy for treatment-resistant Schizophrenia. J Psychopharmacology. 2006b;20(5):683-69. 
101. Leweke FM, Koethe D, Gerth CW, Nolden BM, Schreiber D, Gross S, et al. Double blind, controlled clinical trial of cannabidiol monotherapy versus amisulpride in the treatment of acutely psychotic schizophrenia patients. Schizophr Bull. 2007;33(2):310. In: Zuardi, AW. Cannabidiol: from an inactive cannabinoid to a drug with wide spectrum of action. Rev Bras Psiquiatr. 2008;30(3):271-280.

102. Zuardi AW, Crippa JAS, Hallak JEC, Pinto JP, Chagas MH, Rodrigues GG, et al. Cannabidiol for the treatment of psychosis in Parkinson's disease. J Psychopharmacology. 2009;23(8):979-983.

103. Leweke FM, Kranaster L, Pahlisch F, Klosterkötter F, Hellmich M, Piomelli D, et al. The efficacy of cannabidiol in the treatment of schizophrenia - a translational approach. Schizophr Bull. 2011;37(Supp 1):313.

104. Leweke FM, Giuffrida A, Wurster U, Emrich HM, Piomelli D. Elevated endogenous cannabinoids in schizophrenia. Neuroreport. 1999;10:1665-1669.

105. Watanabe K, Kayano $\mathrm{Y}$, Matsunaga T, Yamamoto I, Yoshimura H. Inhibition of anandamide amidase activity in mouse brain microsomes by cannabinoids. Biol Pharm Bull. 1996;19(8):1109-1111.

106. Leweke FM, Piomelli D, Pahlisch F, Muhl D, Gerth CW, Hoyer C, et al. Cannabidiol enhances anandamide signalling and alleviates psychotic symptoms of schizophrenia. Trans Psychiatry. 2012;94(2):1-7

107. Winton-Brown TT, Allen P, Bhattacharyya S, Borgwardt SJ, Fusar-Poli P, Crippa JA, et al. Modulation of auditory and visual processing by Delta-9-Tetrahydrocannabinol and Cannabidiol: an fMRI study. Neuropsychopharmacol. 2011;36:1340-1348.

108. Borgwardt SJ, Allen P, Bhattacharyya S, Fusar-Poli P, Crippa JA, Seal ML, et al. Neural basis of delta-9-Tetrahydrocannabinol and Cannabidiol: effects during response inhibition. Biol Psychiatry. 2008;64:966-973.

109. Friston KJ, Holmes AP, Worsley KJ. How many subjects constitute a study? Neuroimage. 1999;10:1-5.

110. Fusar-Poli P, Crippa JA, Bhattacharrya S, Borgwardt SJ, Allen P, Martin-Santos R, et al. Distinct effects of delta9-tetrahydrocannabinol and cannabidiol on neural activation during emotional processing. Arch Gen Psychiatry. 2009;66(1):95-105.

111. Bhattacharyya S, Fusar-Poli P, Borgwardt S, Martin-Santos R, Nosarti C, O'Carroll C, et al. Modulation of medio-temporal and ventrostriatal function in humans by delta-9tetrahydrocannabinol: a neural basis for the effects of Cannabis sativa on learning and psychosis. Arch Gen Psychiatry. 2009;66:442-451.

112. Marsicano G, Wotjak CT, Azad SC, Bisogno T, Rammes G, Cascio MG, et al. The endogenous cannabinoid system controls extinction of aversive memories. Nature. 2002;418(6897):530-534.

113. Gaetani S, Cuomo V, Piomelli D. Anandamide hydrolysis: a new target for anti-anxiety drugs? Trends Mol Med. 2003;9(11):474-478.

114. Freund TF, Katona I, Piomelli D. Role of endogenous cannabinoids in synaptic signalling. Physiol Rev. 2003;83(3):1017-1066.

115. Bhattacharrya S, Crippa JA, Allen P, Martin-Santos R, Borgwardt S, Fusar-Poli P, et al. Induction of psychosis by delta9-tetrahydrocannabinol reflects modulation of prefrontal and striatal function during attentional salience processing. Arch Gen Psychiatry. 2012;69(1):27-36.

116. Guillin O, Abi-Dargham A, Laruelle M. Neurobiology of dopamine in schizophrenia. Int Rev Neurobiol. 2007;78:1-39.

117. Kapur S. Psychosis as a state of aberrant salience: a framework linking biology, phenomenology, and pharmacology in schizophrenia. Am J Psychiatry. 2003;160:1323. 
118. Rosier JP, Stephan KE, den Ouden HEM, Barnes TRE, Friston KJ, Joyce EM. Do patients with schizophrenia exhibit aberrant salience? Psychol Med. 2009;39(2):199209.

119. Jensen J, Willeit M, Zipursky RB, Savina I, Smith AJ, Menon M, et al. The formation of abnormal associations in schizophrenia: neural and behavioural evidence. Neuropsychopharmacol. 2008;33(3):473-479.

120. Mikell CB, Mckhann GM, Segal S, McGovern RA, Wallenstein MB, Moore H. The hippocampus and nucleus accumbens as potential therapeutic targets for neurosurgical intervention in schizophrenia. Stereotact Funct Neurosurg. 2009;87:256265.

121. Allen P, Larøi, F, McGuire PK \& Aleman A. The hallucinating brain: a review of structural and functional neuroimaging studies of hallucinations. Neurosci Biobehav Rev. 2008;32:175-179.

122. Jung-Beeman $M$. Bilateral brain processes for comprehgending natural language. Trends Cogn Neurosci. 2005;9:512-518

123. Harpaz, Y, Levkovitz Y, Lavidor M. Lexical ambiguity resolution in Wernicke's area and its right homologue. Cortex. 2009;45:1097-1103.

124. Mo S, Su Y, Chan RC, Liu J. Comprehension of metaphor and irony in schizophrenia during remission: the role of theory of mind and IQ. Psychiatry Res. 2008;157:21-29

125. Pertwee RG. The pharmacology and therapeutic potential of cannabidioL In: Di Marzo, V ED Cannabinoids. Kluwer Academic/Plenum Publishers: New York. 2004;32-83.

126. D'Souza DC, Perry E., MacDougall L, Ammerman Y, Cooper T, Wu YT, Braley G, et al. The psychotomimetic effects of intravenous delta-9-tetrahydrocannabinol in healthy individuals: implications for psychosis. Neuropsychopharmacol. 2004;29:1558-1572.

127. Morrison PD, Zois V, McKeown DA, Lee TD, Holt DW, Powell JF, Kapur S, Murray RM. The acute effects of synthetic intravenous Delta9-tetrahydrocannabinol in healthy individuals: implications for psychosis. Neuropsychopharmacol. 2009;39:1607-1616.

128. Sewell RA, Skosnik PD, Garcia-Sosa I, Ranganathan M, D'Souza DC. Behavioural, cognitive and psychophysiological effects of cannabinoids: relevance to psychosis and schizophrenia. Rev Bras Psiquiatr. 2010;32(Supplement 1):15-30.

129. Meltzer HY, Arvanitis L, Bauer D, Rein W. Placebo controlled evaluation of four novel compounds for the treatment of schizophrenia and schizoaffective disorder. Am J Pharmacol. 2004;161:975-984.

130. Leweke FN, Koethe D. Cannabis and psychioatric disorders: it is not only addiction. Addic Biol. 2008;13:264-275.

131. Koethe D, Giuffrida A, Schreiber D, Hellmich M, Schultze-Lutter F, Ruhrmann S, et al. Anandamide elevation in cerebrospinal fluid in initial prodromal states of psychosis. $\mathrm{Br}$ J Psychiatry. 2009b;194:371-2.

132. Pakkenberg B, Scheel-Krüger J, Kristiansen LV. SchizophreniA From structure to function with special focus on the mediodorsal thalamic prefrontal loop. Acta Psychiatr Scand. 2009;120:345-354.

133. Geldwert D, Norris JM, Feldman IG, Schulman JJ, Joyce MP, Rayport S. Dopamine presynaptically and heterogeneously modulates nucleus accumbens medium-spiny neurone GABA synapses in vitro. BMC Neurosci. 2006;30:7-53.

134. Brady AM, O'Donnell P. Dopaminergic modulation of prefrontal cortical input to nucleus accumbens neurones in vivo. J. Neurosci. 2004;24:1040-1049.

135. Koob GF, Swerdlow NR. The functional output of the mesolimbic dopaminergic system. Ann NY Acad Sci. 1988;537:216-227.

136. Jones DL, Mogenson GJ. Nucleus accumbens to globus pallidus GABA projection: electrophysiological and iontophoretic investigations. Brain Res. 1980;188:93-105. 
137. Kalivas PW, Churchill L, Romanides A. Invement of the pallidal-thalamocortical circuit in adaptive behaviour. Ann NY Acad Sci. 1999;877:64-70.

138. Mouslech Z, Valla V. Endocannabinoid system: an overview of its potential in current medical practice. Neuroendocrinology Letters. 2009;30:153-179.

139. Mátyás F, Yanovsky Y, Mackie K, Kelsch W, Misgeld U, Freund TF. Subcellular localization of type 1 cannabinoid receptors in the rat basal ganglia. Neurosci. 2006;137:337-361.

140. Brown AJ. Novel cannabinoid receptors. Br J Pharmacol. 2007;152:67-75.

141. Ryberg E, Larsson N,Sjögren S, Hjorth S, Hermansson NO, Leonova J, Elebring T, et al. The orphan receptor GPR55 is a novel cannabinoid receptor. $\mathrm{Br} \mathrm{J}$ Pharmacol. 2007;152(7):1092-1101.

142. Cristino L, de Petrocellis L, Pryce G, Baker D, Pryce G, Baker D, Guglielmotti V, et al. Immunohistochemical localization of cannabinoid type 1 and vanilloid transient receptor potential vanilloid type 1 receptors in the mouse brain. Neurosci. 2006;139:1405-1415.

143. Di Marzo V, Bisogno T, De Petrocellis L. Anandamide: some like it hot. Trends Pharmacol Sci. 2001;22:346-349

144. Xing J, Li J. TRPV1 receptor mediates glutamatergic synaptic input to dorsolateral periaqueductal gray (d1PAG) neurones. J Neurophysiol. 2007;97:503-511

145. Szallasi A, Blumberg PM. Vanilloid (Capsaicin) receptors and mechanisms. Pharmacol Rev. 1999;51:159-212.

146. Carrier EJ, Auchampach JA, Hillard CJ. Inhibition of an equilibrative nucleoside transporter by cannabidiol: a mechanism of cannabinoid immunosuppression. Proc Natl Acad Sci USA. 2006;103(20):7895-7900.

147. Chaves C, Marque CR, Trzesniak C, Machado DE, Sousa JP, Zuardi AW, Crippa JA, et al. Glutamate-N-methyl-D-aspartate receptor modulation and minocycline for the treatment of patients with schizophrenia: an update. Braz $\mathrm{J}$ Med Biol Res. 2009;42:1002-1014.

148. Zuardi AW, Crippa JA, Hallak JE. Cannabis sativa: the plant that can induce unwanted effects and also treat them. Rev Bras Psiquiatr. 2010;32(Supp 1):1-2.

149. Potkin SG, Saha AR, Kujawa MJ, Carson WH, Ali M, Stock E, et al. Aripiprazole, an antipsychotic with a novel mechanism of action, and Risperidone vs placebo in patients with schizophrenia and schizoaffective disorder. Arch Gen Psychiatry. 2003;60:681-690.

150. Gomes FV, Resstel LB, Guimarães FS. The anxiolytic-like effects of cannabidiol injected into the bed nucleus of the stria terminalis are mediated by 5-HT1A receptors. Psychopharmacology. 2011;213:465-473.

151. Resstel LB, Tavares RF, Lisboa SF, Joca SR, et al.5-HT1A receptors are involved in the cannabidiol-induced attenuation of behavioural and cardiovascular responses to acute restraint stress in rats. Br J Psychopharmacology. 2009;156:181-188.

152. Zanelati TV, Biojone C, Moreira FA, Guimarães FS, Joca SR. Antidepressant-like effects of cannabidiol in mice: possible involvement of $5-\mathrm{HT}_{1 a}$ receptors. $\mathrm{Br} \mathrm{J}$ Pharmacol. 2010;159:122-128.

153. Russo EB, Burnett A, Hall B, Parker KK. Agonistic properties of cannabidiol at 5-HT1a receptors. Neurochem Res. 2005b;30(8):1037-1043.

154. Guimarães FS, Chiaretti TM, Graeff FG, Zuardi AW. Antianxiety effect of cannabidiol in the elevated plus-maze. Psychopharmacology. 1990;100:558-559

155. Guimarães FS, de Aguiar JC, Mechoulam R, Breuer A. Anxiolytic effect of cannabidiol derivatives in the elevated plus-maze. Gen Pharmacol. 1994;25:161-164. 
156. Wolf SA, Bick-Sander A, Fabel K, Leal-Galicia P, Tauber S, Ramirez-Rodriguez G, et al. (2010) Cannabinoid receptor CB1 mediates baseline and activity-induced survival of new neurons in adult hippocampal neurogenesis. Cell Commun Signal. 2010;8:12

157. Reif A, Fritzen S, Finger M, Strobel A, Lauer M, Schmitt A, et al. Neural stem cell proliferation is decreased in schizophrenia, but not in depression. Mol. Psychiatry. 2006;11:514-522.

158. Reif A, Schmitt A, Fritzen S, Lesch KP. Neurogenesis and schizophrenia: dividing neurons in a divided mind? Eur Arch Psy Clin N. 2007;257:290-299

159. Hampson AJ, Grimaldi M, Axelrod J, Wink D. Cannabidiol and delta 9tetrahydrocannabinol are neuroprotective antioxidants Proc Natl Acad Sci. 1998;95(14):8268-8273.

160. Desfossés J, Stip E, Bentaleb LA, Potvin S. Endocannabinoids and Schizophrenia. Pharmaceuticals. 2010;3:3101-3126. DOI: 10.3390/ph3103101.

161. Burnstein S. PPAR-: A Nuclear receptor with affinity for cannabinoids. Life Sci. 2005:77; 1674-1684.

162. Panlilio LV, Justinova Z, Goldberg SR. Inhibition of FAAH and activation of PPAR: New approaches to the treatment of cognitive dysfunction and drug addiction. Pharmacol Ther. 2013:138;84-102.

163. Sun Y, Bennett A. Cannabinoids: a new group of agonists of PPARs. PPAR Res; 2007. DOI: $10.1155 / 2007 / 23513$

164. Pertwee RG. The pharmacology of cannabinoid receptors and their ligands: an overview. Int J Obesity. 2006;30:S13-S18.

165. Bordet R, Ouk T, Petrault O, Gelé P, Gautier S, Laprais M, Deplanque D, Duriez P, Staels B, Fruchart JC, Bastide M. PPAR: a new pharmacological target for neuroprotection in stroke and neurodegenerative diseases. Biochem Soc Trans. 2006;34:1341-1346.

166. Carroll CB, Zeissler ML, Hanemann CO, Zajicek JP. $\Delta^{9}$-tetrahydrocannabinol $\left(\Delta^{9}\right.$ THC) exerts a direct neuroprotective effect in a human cell culture model of Parkinson's disease. Neuropathol Appl Neurobiol. 2012:38(6);535-47. DOI: 10.1111/j.1365-2990.2011.01248.x.

167. Esposito G, Scuderi C, Valenza M, Togna GI, Latina V, De Filippis D, et al. Cannabidiol Reduces $A \beta$-Induced Neuroinflammation and Promotes Hippocampal Neurogenesis through PPARy Involvement. PLoS ONE. 2011:6(12). DOI:10.1371/journal.pone.0028668

168. Mecha M, Torrao AS, Mestre L, Carrillo-Salinas FJ, Mechoulam R, Guaza C. Cannabidiol protects oligodendrocyte progenitor cells from inflammation-induced apoptosis by attenuating endoplasmic reticulum stress. Cell Death Dis. 2012:28. DOI: 10.1038/cddis.2012.71.

(C) 2013 Jalali and Johnson; This is an Open Access article distributed under the terms of the Creative Commons Attribution License (http://creativecommons.org/licenses/by/3.0), which permits unrestricted use, distribution, and reproduction in any medium, provided the original work is properly cited.

Peer-review history:

The peer review history for this paper can be accessed here: http://www.sciencedomain.org/review-history.php?iid=293\&id=29\&aid=2248 